KfK 3254 ORNL/TM-7891

Dezember 1981

\title{
Pressure Drop and Heat Transfer Correlations for Use in CFTL Bundle Analysis
}

S. A. Hodge, L. Meyer Institut für Neutronenphysik und Reaktortechnik

\section{Kernforschungszentrum Karlsruhe}




\section{KERNFORSCHUNGSZENTRUM KARLSRUHE}

Institut für Neutronenphysik und Reaktortechnik

KfK 3254

Pressure Drop and Heat Transfer Correlations for Use in CFTL Bundle Analysis

S.A. Hodge and L. Meyer

Dieser Bericht erscheint gleichzeitig als Report ORNL/TM-7891 des Oak Ridge National Laboratory, Oak Ridge, Tennessee 37830.

Kernforschungszentrum Karlsruhe $\mathrm{GmbH}$, Karlsruhe 
Als Manuskript vervielfältigt

Für diesen Bericht behalten wir uns alle Rechte vor

Kernforschungszentrum Karlsruhe GmbH

ISSN 0303-4003 


\title{
PRESSURE DROP AND HEAT TRANSFER CORRELATIONS FOR USE IN CFTL BUNDLE ANALYSIS
}

\author{
S. A. Hodge* $\quad$ L. Meyer \\ ABSTRACT
}

The friction factor and Stanton number for flow past a roughened surface are determined by the parameters $A$ and $R\left(h^{+}\right)$of the universal law of friction and the parameters $A_{H}$ and $G\left(h^{+}\right)$of the universal law of heat transfer. The methods used for experimental determination of these parameters for the particular roughness and rod diameter proposed for use in the Core Flow Test Loop (CFTL) are presented and recommended values for use in CFTL bundle flow analysis are prescribed.

\section{Beziehungen fïr Druckverlust und Wårmeübergang fiix die Analyse von CFTL-Stabbündeln}

\section{Zusammenfassung}

Reibungsbeiwert und Stantonzahlen für die Strömung über rauhe Oberflächen sind bestimmt durch die Parameter $A$ und $\mathrm{R}\left(\mathrm{h}^{+}\right)$des Wandgesetzes für die Geschwindigkeitsverteilung und die Parameter $A_{H}$ und $G\left(h^{+}\right)$des Wandgesetzes für die Temperaturverteilung. Die Methoden zur experimentellen Bestimmung dieser Parameter werden dargelegt für die spezielle Rauhigkeit und den Stabdurchmesser, die für die Untersuchungen in Core Flow Test Loop (GFTL) vorgeschlagen wurden. Empfohlene Werte für die Analyse der CFTL-Stabbündel werden angegeben.

* Technical staff member, Oak Ridge National Laboratory (ORNL) 
CONTENTS

page

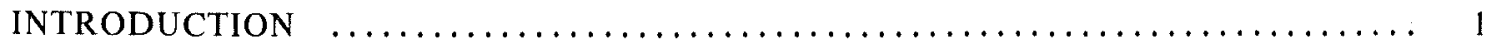

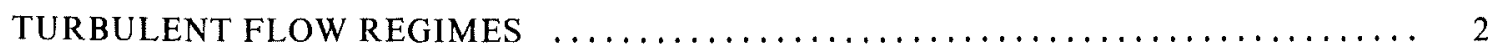

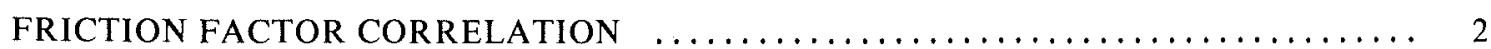

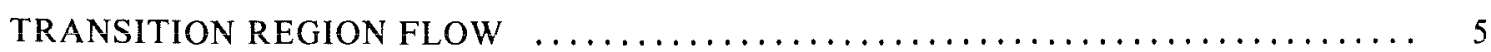

EFFECT OF TEMPERATURE ON FRICTION FACTOR $\ldots \ldots \ldots \ldots \ldots \ldots \ldots \ldots \ldots . \ldots$

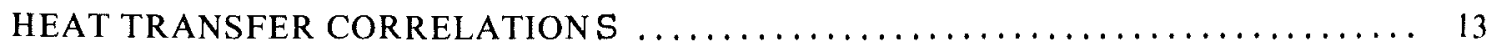

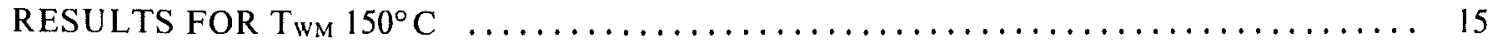

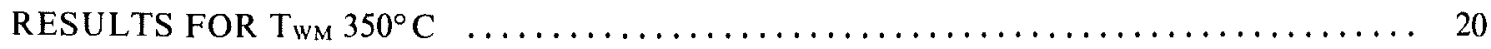

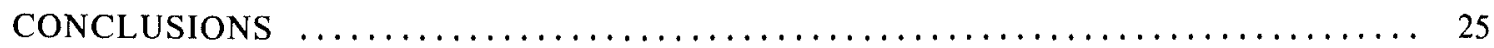

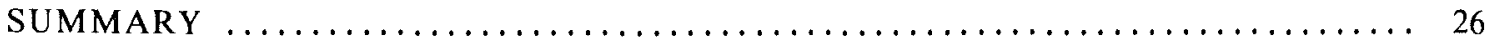

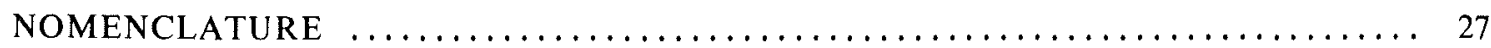

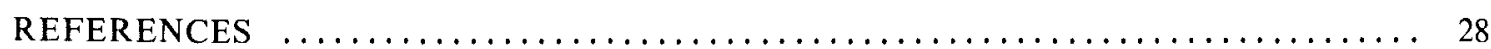

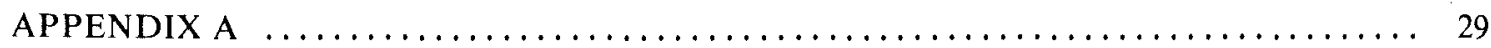

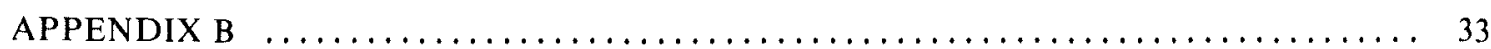

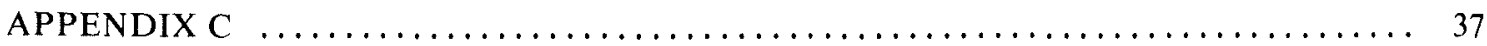




\section{INTRODUCTION}

The Core Flow Test Loop (CFTL) was designed at Oak Ridge National Laboratory (ORNL) to be a high temperature, high pressure system for the circulation of helium coolant in axial flow through a bundle of electrically heated fuel rod simulators (FRS) under steady state and transient conditions. The fuel rod simulators were designed to be typical of GCFR application, with the cladding surface roughened over the heated length.

The initial test rod bundle planned for installation in the CFTL was a 37 rod bundle consisting of 34 roughened and heated FRS plus three larger-diameter, roughened but unheated grid spacer support rods. This bundle is enclosed in a smooth hexagonal duct; its construction is shown in Fig. 1 of Ref. 1 and comprises four types of flow channel. These are:

1. central channels, bounded by three heated FRS;

2. support rod channels, bounded by two heated FRS and an unheated spacer grid support rod;

3. wall channels, bounded by two FRS and the smooth duct wall; and

4. corner channels, bounded by one FRS and an interior angle of the duct wall.

The ratio of the velocity profile width to the roughness rib height is important to the determination of the friction factor and Stanton number for flow past a particular roughened surface. A profile of the actual roughness machined on the CFTL FRS cladding surface is shown in Appendix A; this roughness has a trapezoidal shape, a roughness rib height of $0.13 \mathrm{~mm}$, a pitch-to-height ratio of 12 , and a width-to-height ratio of 3.5. These dimensions produce a volumetric radius $\dagger$ of $3.918 \mathrm{~mm}$ for the CFTL fuel rod simulators and a volumetric radius of $4.718 \mathrm{~mm}$ for the larger-diameter unheated grid spacer support rods.

The velocity profile width is defined as the separation distance between the volumetric surface of a roughened rod and the surface of zero net momentum transfer, or shear, in the adjacent flow. This distance varies among the four CFTL channel types due to the differing geometries. In the wall and corner channels, it is also a function of the flow because the surface of zero shear moves outward from the roughened rod surface toward the smooth duct wall as the Reynolds number increases. ${ }^{2}$

†The volumetric radius of a roughened rod is defined as the radius which would prevail if the volume of the roughness elements were smeared evenly over the rod surface. 
In view of the wide range of velocity profile widths which would exist simultaneously within the various channels of the proposed CFTL test bundle, it was deemed essential to an accurate analysis of the CFTL flows that correlations expressing the dependence of friction factor and Stanton number upon velocity profile width be established experimentally for the particular CFTL roughness. The experiments to this purpose were conducted at KfK, Karlsruhe, FRG.

\section{TURBULENT FLOW REGIMES}

It was shown by Nikuradse $\mathrm{N}^{3}$ that turbulent flow* past a roughened surface can be characterized by one of three flow regimes, depending on the nature of the variation of the friction factor with the Reynolds number of the flow. At relatively low flow in the turbulent range, the friction factor varies with the Reynolds number in the same manner as in turbulent flow past a smooth surface, and the flow is said to be "hydraulically smooth." As the Reynolds number is increased, the thin region near the wall in which the flow field is dominated by the fluid viscosity narrows so that the roughness elements protrude to an increasing extent into the main flow stream, generating an increased frictional pressure loss by the mechanism of form drag. After this "transition region," the roughness elements are fully exposed to the main flow stream and the frictional pressure loss is virtually all due to form drag. Thus, at sufficiently high Reynolds numbers, the friction factor becomes independent of the Reynolds number and the flow characterized by a constant friction factor is termed "fully rough."

Each of these three turbulent flow regimes would exist within the roughened portion of the CFTL bundle at some time during the planned test schedule. For tests at low bundle flow, fully rough flow would exist in the central and support rod channels concurrent with transition region and/or hydraulically smooth flow in the wall and corner channels. $\uparrow$ While existing relations applicable to flow past smooth walls could be used in the analysis of hydraulically smooth flow within the CFTL bundle, there was a need for development of correlations for the variation of friction factors and Stanton numbers with velocity profile width in both the transition and fully rough regimes of flow. It was also important to establish the Reynolds number range in which each correlation applies, that is, to establish the extent of the transition region.

\section{FRICTION FACTOR CORRELATION}

A friction factor for flow past roughened surfaces is defined in a manner similar to that for smooth surfaces. The friction factor for rough surface flow is defined as the proportionality factor $f_{1}$ in the equation

$$
\tau_{\mathrm{w}}=\mathrm{f}_{\mathrm{l}} \frac{\rho_{1} \overline{\mathrm{u}}_{1}^{2}}{2}
$$

for the axially averaged shear stress $\tau_{w}$ at the rough wall. The terms $\rho_{1}$ and $\bar{u}_{1}$ in this equation represent the density and the spacially averaged velocity for the flow between the rough wall and the surface of zero shear in the adjacent flow.

\footnotetext{
* Laminar flow past a roughened surface can be treated in the same manner as laminar flow past a smooth surface, except that the flow passage should be considered to be that defined by the roughness rib tips.

$\dagger$ The wall and corner channels are bounded by both rough (rod) and smooth (duct wall) surfaces. By design, these channels have much larger wetted perimeters and consequently, significantly lower Reynolds numbers than the bundle average.
} 
The friction factor $f_{1}$ can be related to the velocity profile width $Y_{L}$ in the adjacent flow by the universal law of friction for flow past rough surfaces. ${ }^{2}$ For flow in an annular geometry such as that formed by axial flow over the surface of one of the rough rods in a rod bundle, this law can be written as the linear equation

$$
\sqrt{2 / f_{1}}=A\left[\ln \left(Y_{L} / h\right)-\frac{1}{2}-\frac{1}{2+Y_{L} / r_{1}}\right]+R\left(h^{+}\right)
$$

The term $h$ in Eq. (2) represents the height of the roughness rib above the root, while $r_{1}$ is the volumetric radius of the rough rod. The parameters $A$ and $R\left(h^{+}\right)$are independent of Reynolds number in fully rough flow. Mathematically, the parameter $A$ is the gradient of the linear portion of the dimensionless velocity profile while $\mathrm{R}\left(\mathrm{h}^{+}\right)$is the value of the dimensionless velocity at a point $h$ units above the surface. However, recent experiments by Meyer and $\mathrm{Vogel}^{5}$ in a parallel plate geometry have shown that the gradient of the linear portion of the dimensionless velocity profile varies with the velocity profile width and can differ significantly from the slope $A$ of the linear relation of Eq. (2). This discrepancy is probably due to the known physical deviation of the dimensionless velocity profile from linearity both near the rough wall and near the surface of zero shear. The effect of these deviations on the average value of the dimensionless velocity, which is directly related to the friction factor by the equation

$$
\overline{\mathrm{u}}_{\mathrm{i}}^{+}=\sqrt{2 / \mathrm{f}_{1}}
$$

will vary with the velocity profile width since a smaller fraction of the dimensionless velocity profile will be linear in a small channel with a short velocity profile.

In fully rough flow, the parameters $A$ and $R\left(h^{+}\right)$of Eq. (2) become constant values. These values have been determined for the CFTL roughness by testing a single prototype rod in three different annular geometries; each geometry was formed by placing the rough rod at the center of one of a series of three smooth tubes of varying diameter. A discussion of the experimental apparat us and procedure is provided in the appendix.

The friction factors $f_{1}$ and the corresponding velocity profile widths $\left(Y_{L}\right)$ were determined for various flows adjacent to the rough rod in each of the three annular geometries using the experimentally measured values for axial pressure drop and flow, and application of the Dalle Donne-Meyer transformation. ${ }^{6,7}$ The slope A and intercept $\mathrm{R}\left(\mathrm{h}^{+}\right)$of Eq. (2) were then determined by plotting the friction factor term $\sqrt{ } 2 / f_{1}$ as a function of the velocity profile width term given by

$$
\left[\ln \left(\mathrm{Y}_{\mathrm{L}} / \mathrm{h}\right)-\frac{1}{2}-\frac{1}{2+\mathrm{Y}_{\mathrm{L}} / \mathrm{r}_{1}}\right]
$$

The graphical interpretation for the results representative of fully rough flow is shown in Fig. 1.

Three distinct clusters of points are shown in Fig. 1. Each cluster contains the points representative of isothermal axial flow past the CFTL rod in one of the three smooth outer tubes, over a range of Reynolds numbers in the fully rough flow regime. The parameter $Y_{T}(\mathrm{~mm})$, which represents the distance from the volumetric surface of the rough rod to the inner surface of the smooth tube, is indicated for each of the three annular geometries. As delineated in Fig. 1, the intercept $\mathrm{R}\left(\mathrm{h}^{+}\right)$and slope 


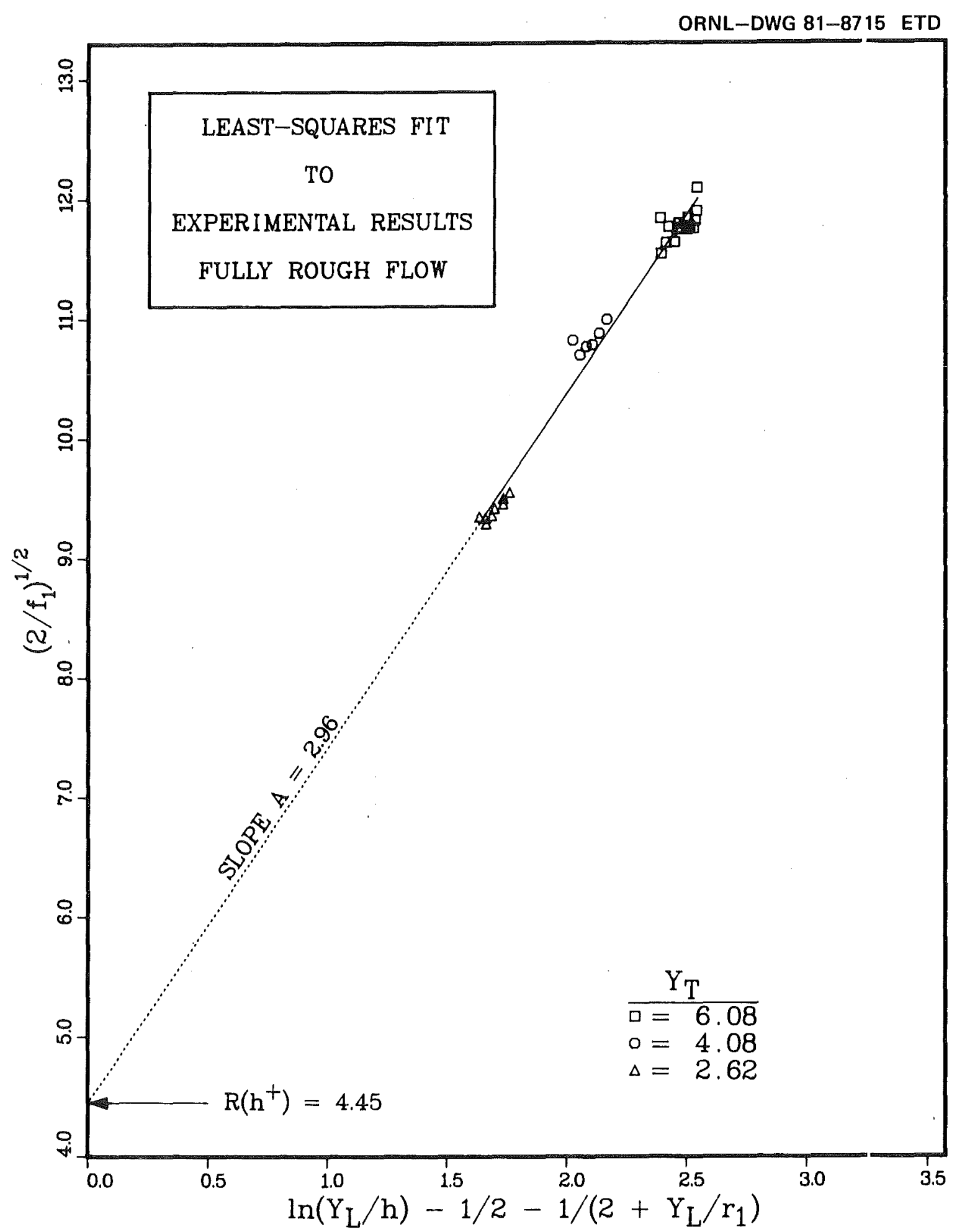

Fig. 1. The universal law of friction for the CFTL rod. 
A for use in Eq. (2) for calculation of the friction factors within the CFTL bundle in fully rough flow have values of 4.45 and 2.96 , respectively.

\section{TRANSITION REGION FLOW}

The parameters $R\left(h^{+}\right)$and $A$ become constant in fully rough flow because the friction factor is independent of the Reynolds number; this is not the case for flows within the range of the transition region. The friction factor can be expressed as a function of the Reynolds number, but it is more common to characterize flow in the transition region as a function of the roughness Reynolds number $\mathrm{h}^{+}$, where

$$
\mathrm{h}^{+}=\frac{\mathrm{hu} *}{\nu}=\frac{\mathrm{h}}{\mathrm{D}} \operatorname{Re} \sqrt{\mathrm{f}_{1} / 2}
$$

The roughness Reynolds number is preferred because it is not a function of the hydraulic diameter. Thus, for single-rod tests in a succession of annular geometries with differing hydraulic diameters, the flow will become fully rough at different Reynolds numbers, but at the same value of $\mathrm{h}^{+}$, since the roughness height would not change in these tests.

The procedure employed to determine values for the parameters $R\left(h^{+}\right)$and $A$ for use in Eq. (2) for flows in the transition region is basically the same as that used for fully rough flow. However, to prepare a graph of Eq. (2) in the transition region, it is necessary that each ordinate value $\sqrt{2 / f_{1}}$ be plotted as a function of the abcissa value [Eq. (4)] which corresponds to the same roughness Reynolds number $\left(\mathrm{h}^{+}\right)$. To this end, it is useful to first separately plot the ordinate and the abcissa values as functions of $\mathrm{h}^{+}$.

A semilogarithmic plot of the ordinate values $\sqrt{2 / f_{1}}$ as a function of $h^{+}$for the CFTL rod is shown in Fig. 2. Each of the three curves represents the experimental results for a different annular geometry; the parameter $Y_{T}(\mathrm{~mm})$ that differentiates the curves is the annular gap, which is the distance between the volumetric surface of the rough rod and the inner surface of the smooth outer tube. The nearly vertical lines which indicate a rapid decrease in the friction factor $\left(f_{1}\right)$ with increasing $h^{+}$at very low values of $\mathrm{h}^{+}$are least-squares fits to the experimental results obtained for laminar flow. Following the transition to turbulent flow, it can be seen that the friction factor $\left(f_{1}\right)$ increases with $\mathrm{h}^{+}$in the transition zone, then becomes constant (within the limits of experimental error) as the flow becomes fully rough at an $\mathrm{h}^{+}$value of about 20 .

The curved lines representing the results for flow in the transition region are least-squares fits to the plotted data for the two smaller annular geometries. However, for the uppermost curve which represents the results for flow in the $20 \mathrm{~mm}\left(\mathrm{Y}_{\mathrm{T}}=6.08 \mathrm{~mm}\right)$ geometry, the least-squares fit was derived without consideration of the three points lying in the range of $\mathrm{h}^{+}$values between 3 and 9 ; these points can be seen to lie significantly below the uppermost dotted line. Subsequent to completion of the isothermal tests in the $20 \mathrm{~mm}$ smooth tube, the pressure transducer used for some of the readings at low flows was found to be out-of-calibration; this is believed to be the source for the anomalous behavior of the experimental results for low isothermal flow in the $20 \mathrm{~mm}$ tube. Fortunately, the geometries of the four channel types included in the CFTL bundle design would result in velocity profile widths which lie between those in the two smaller annular test geometries. 


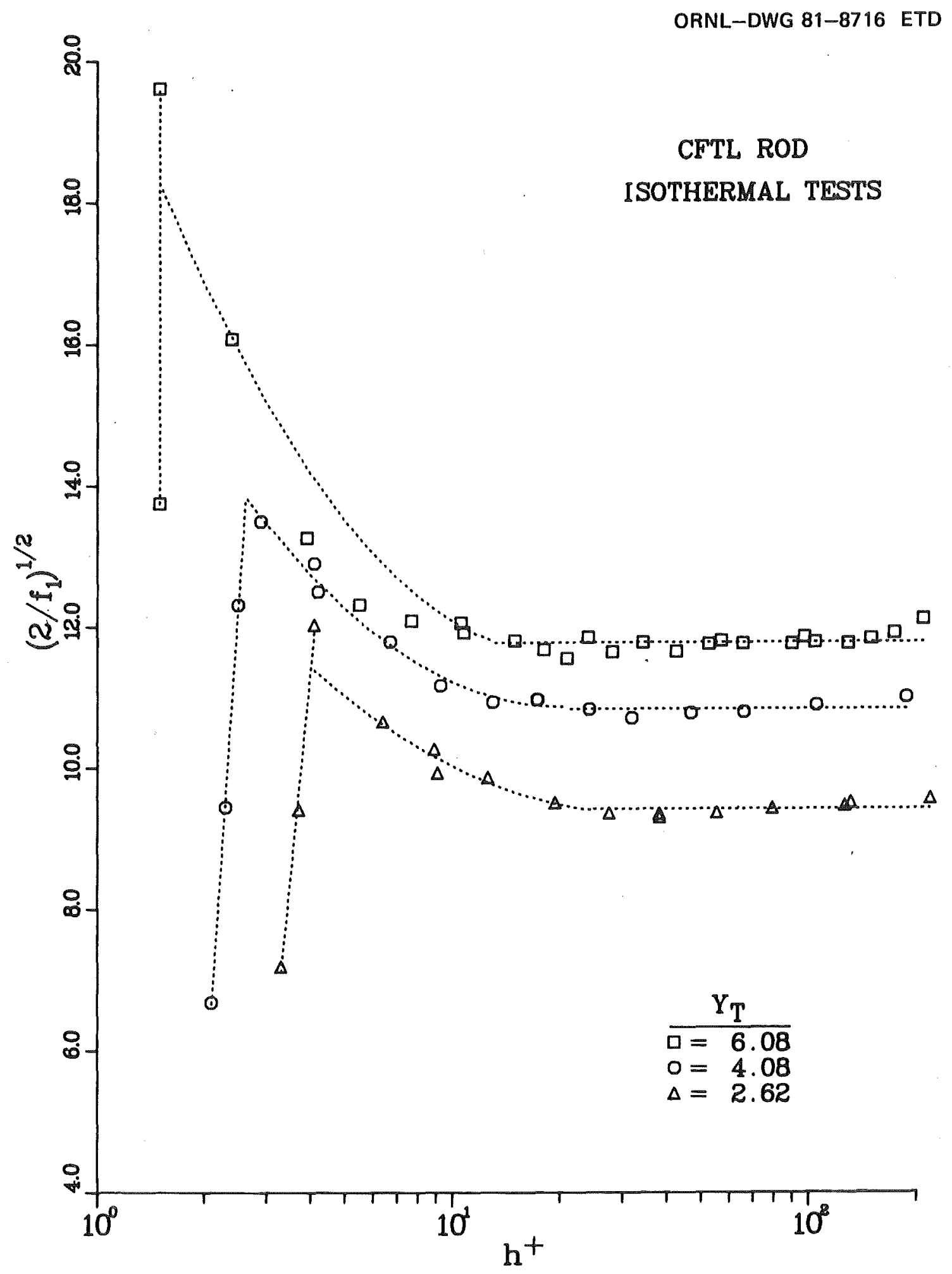

Fig. 2. Variation of ordinate values with roughness Reynolds number in the transition zone. 
The correlation for the least-squares curve-fits to the transition zone results shown in Fig. 2 are of the form

$$
\sqrt{2 / f_{1}}=C_{1}+C_{2} \ln \left(h^{+}\right)+C_{3}\left[\ln \left(h^{+}\right)\right]^{2}
$$

The values of the constants for use in Eq. (6) for each of the annular test geometries are listed in Table 1. It is also important to note from the results displayed in Fig. 2 that the transition zone for flow within the channels of the CFTL bundle can be expected to extend over the range of roughness Reynolds numbers $\left(\mathrm{h}^{+}\right)$from about 3 to 20 .

$\begin{aligned} & \text { Table 1. Constants for the correlation } \\
& \text { of } \sqrt{2 / f_{1}} \text { with } \text { ?n(h } \\
& \left.{ }^{+}\right) \text {per Eq. (6) }\end{aligned}$
\begin{tabular}{lllll}
\hline $\begin{array}{c}\text { Annular } \\
\text { gap } Y_{T} \\
(\mathrm{~mm})\end{array}$ & $\mathrm{C}_{1}$ & $\mathrm{C}_{2}$ & $\mathrm{C}_{3}$ \\
\hline 6.08 & & & \\
\hline 4.08 & 17.527 & -5.973 & 1.001 \\
2.62 & 17.868 & -5.425 & 0.869 \\
\hline
\end{tabular}

The values on the abcissa [Eq. (4)] are plotted as functions of $\mathrm{h}^{+}$on the semilogarithmic plot of Fig. 3. The modest but continuous increase in these values with $\mathrm{h}^{+}$is caused by a slight movement of the surface of zero shear outward from the rough rod toward the inner surface of the smooth tube as the velocity of the flow increases. It should be noted that this increase in the velocity profile width $\left(Y_{L}\right)$ with the roughness Reynolds number occurs in fully rough flow as well, albeit at a reduced rate.

The constants for the correlation of Eq. (4), that is,

$$
\ln \left(\mathrm{Y}_{\mathrm{L}} / \mathrm{h}\right)-1 / 2-1 /\left(2+\mathrm{Y}_{\mathrm{L}} / \mathrm{r}_{1}\right)=\mathrm{C}_{4}+\mathrm{C}_{5} \ln \left(\mathrm{h}^{+}\right)+\mathrm{C}_{6}\left[\ln \left(\mathrm{h}^{+}\right)\right]^{2}
$$

obtained by a least-squares fit to the curves of Fig. 3 are listed in Table 2.

$\begin{aligned} & \text { Table 2. Constants for the correlation } \\
& \text { of Eq. (4) with } \ln \left(\mathrm{h}^{+}\right) \text {per Eq. (7) }\end{aligned}$
\begin{tabular}{lllll}
\hline $\begin{array}{l}\text { Annular } \\
\text { gap } \mathrm{Y}_{\mathrm{T}} \\
(\mathrm{mm})\end{array}$ & $\mathrm{C}_{4}$ & $\mathrm{C}_{5}$ & $\mathrm{C}_{6}$ \\
\hline 6.08 & & & \\
\hline 4.08 & 1.658 & 0.346 & -0.035 \\
2.62 & 0.929 & 0.324 & -0.032 \\
\hline
\end{tabular}

Derived ordinate values can be plotted against the corresponding values on the abcissa at selected values of the roughness Reynolds number by using these least squares polynomial fits for both the ordinate and the abcissa terms of Eq. (2): The result is shown in Fig. 4 for four values of $h^{+}$in the transition zone at uniform intervals ranging from 5 to 20 . The lowest plotted line in this figure is 


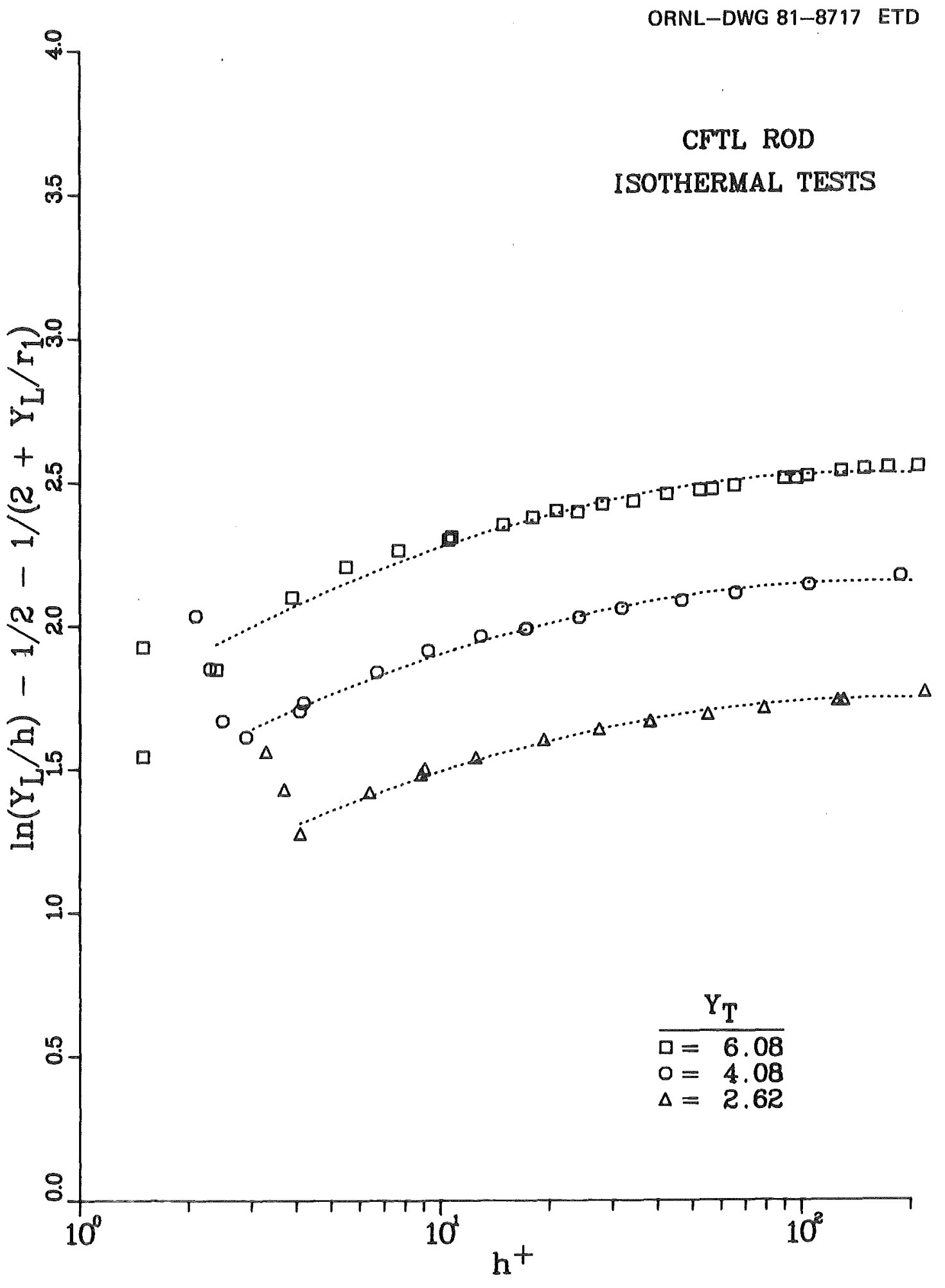

Fig. 3. Variation of abscissa values with roughness Reynolds number in the transition zone. 
ORNL-DWG 81-8718 ETD

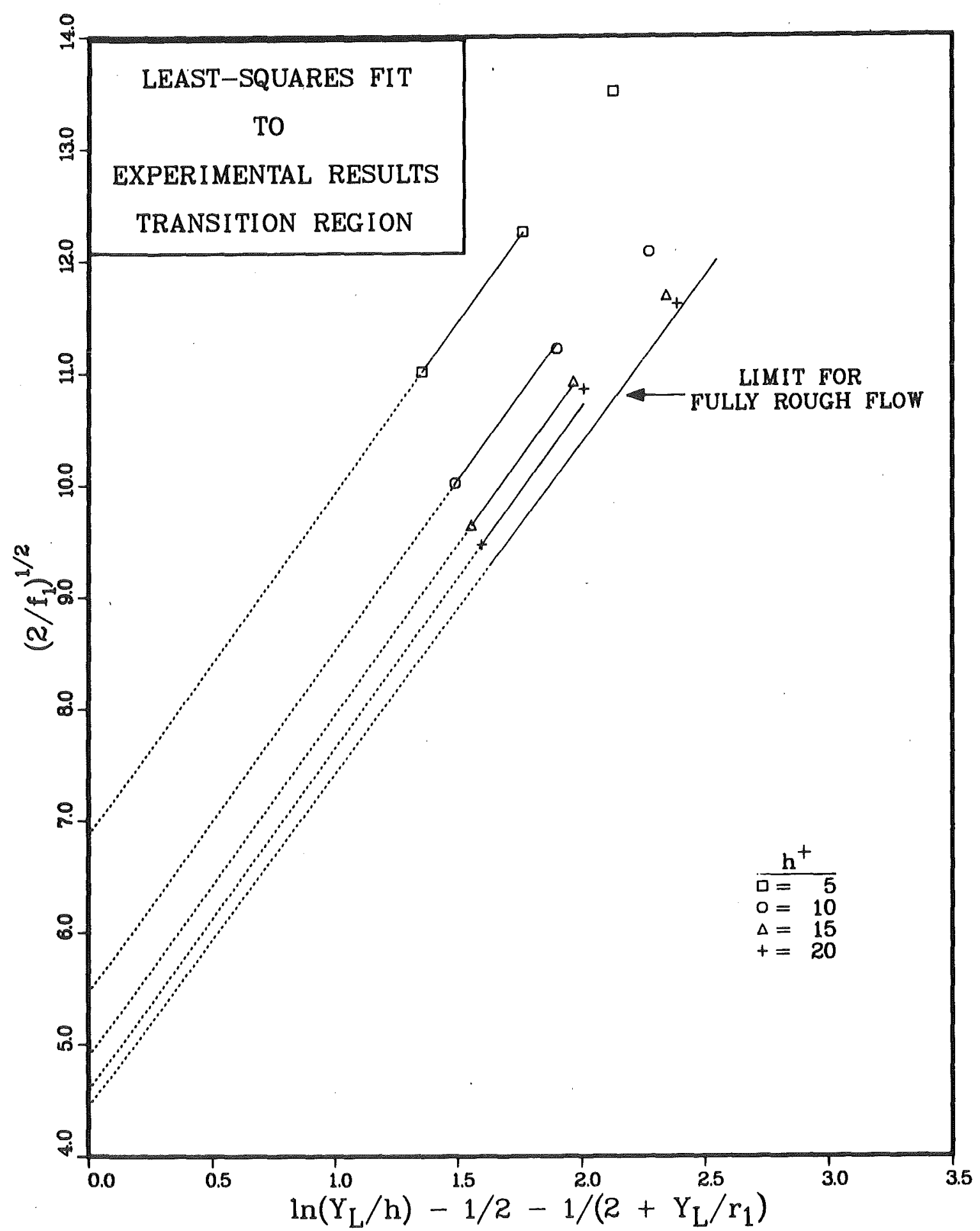

Fig. 4. The universal law of friction for the CFTL rod in the transition region. 
identical to the line plotted in Fig. I and represents the limiting relation between $\sqrt{2 \cdot f_{1}}$ and Eq. (4) reached as the value of $\mathrm{h}^{+}$increases into the regime of fully rough flow.

In the transition region at $\mathrm{h}^{+}$values of 20 or below, the points plotted in Fig. 4 representing flow in the two smaller annular geometries have been connected by straight solid lines; these lines have been extended to the ordinate axis by dotted lines. As was illustrated in Fig. I for the case of fully rough flow, the slopes of these lines represent the parameter $A$ and the ordinate intercepts represent the parameter $\mathrm{R}\left(\mathrm{h}^{+}\right)$at the particular value of $\mathrm{h}^{+}$for which each line was drawn. The points representing transitional zone flow past the rough rod in the $20 \mathrm{~mm}$ smooth tube shroud were not considered in the establishment of these values because of the experimental difficulty mentioned previously and because the CFTL. channel geometries lie between those of the two smaller annular test geometries.

As shown in Fig. 4, the roughness parameters for CFTL rod in the transition zone can best be modeled by the assumption that the slope A remains constant at the value obtained for fully rough flow.

$$
A=2.96
$$

with a corresponding dependence of the ordinate intercept upon the roughness Reynolds number given by

$$
\mathrm{R}\left(\mathrm{h}^{+}\right)=8.695-0.423\left(\mathrm{~h}^{+}\right)+0.011\left(\mathrm{~h}^{+}\right)^{2}
$$

over the range $5 \leqslant \mathrm{~h}^{+} \leqslant 20$. The use of these parameters in Eq. (2) will permit accurate determination of the friction factors for transition zone flow in any of the channels in the CFTL bundle design.

\section{EFFECT OF TEMPERATURE ON FRICTION FACTOR}

The previous discussion has concerned only the test results for isothermal flow. The term $\sqrt{2 / f_{1}}$ is plotted as a function of $\mathrm{h}^{+}$for three different heating conditions within each of the smooth tube shrouds in Fig. 5. It should be noted that the scale of the ordinate is expanded, and there is no discernible effect of temperature for determinations with the 13-mm smooth tube shroud, denoted "shroud 13 " on the figure. However, there is a slight decrease of friction factor with increasing temperature for flow in shroud 16, and a marked temperature effect is observed for the test results in shroud 20 . Since the velocity profile widths for the various channels of the CFTL bundle fall between those modeled by shrouds 16 and 13, the expressions previously developed for determination of the parameters $A$ and $\mathrm{R}\left(\mathrm{h}^{+}\right)$in isothermal flow should give satisfactory results for a CFTL bundle flow analysis.

In Fig. 6, a temperature correction of the form

$$
\sqrt{2 / f_{1}}=\sqrt{2 / f_{1}}\left(T_{W} / T_{B}\right)^{-0.10}
$$

has been applied to all of the plotted data. This temperature correction is equivalent to the correction

$$
f_{1}=f_{1}\left(T_{W} / T_{B}\right)^{-0.20}
$$

and does reduce the scatter of data for the flows in shroud 20 . However, as would be expected, this temperature correction spreads the originally closely grouped data for flow in the two smaller annular geometries and is therefore not recommended for CFTL application. 


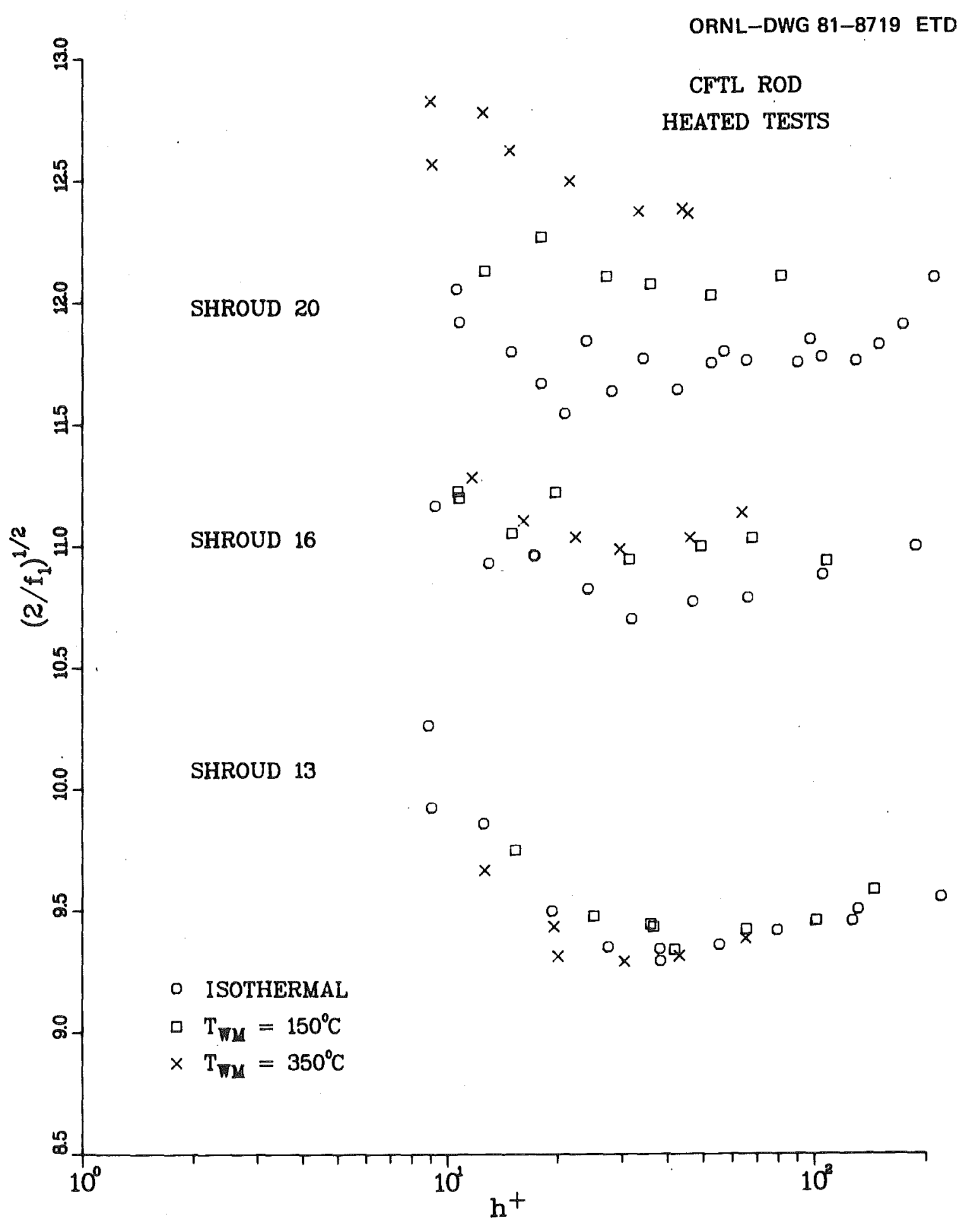

Fig. 5. Effect of temperature on ordinate values. 


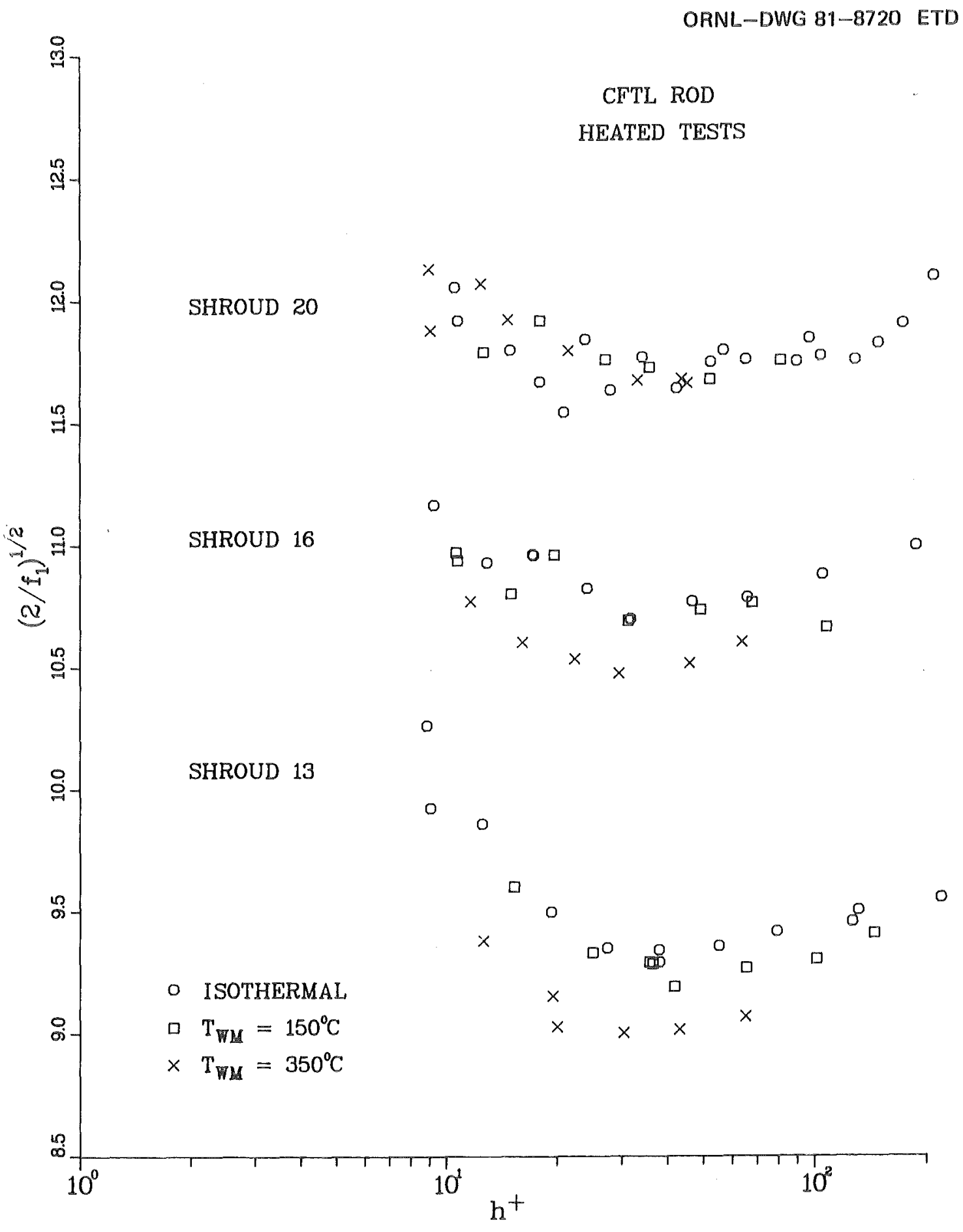

Fig. 6. Application of temperature correction to ordinate values. 


\section{HEAT TRANSFER CORRELATIONS}

The universal law of heat transfer for flow in an annular geometry can be written in the form ${ }^{2}$

$$
\frac{\sqrt{f_{i} / 2}}{S t_{1}}=A_{H}\left[\ln \left(Y_{L} / h\right)-\frac{1}{2}-\frac{1}{2+Y_{L} / r_{1}}\right]+G\left(h^{+}\right)
$$

This law expresses the ratio of the term $\sqrt{f_{1} / 2}$ to the Stanton number $\mathrm{St}_{1}$, which is applicable to the region of flow between the volumetric surface of the rough rod and the surface of zero shear. This Stanton number is defined by the equation

$$
\mathrm{St}_{1}=\frac{\mathrm{q}_{\mathrm{w}}}{\left(\mathrm{T}_{\mathrm{w}}-\mathrm{T}_{\mathrm{B} 1}\right) \rho_{1} \mathrm{C}_{\mathrm{p}} \overline{\mathrm{u}}_{1}}
$$

where $T_{B 1}$ is the bulk temperature of the coolant in the region adjacent to the rough surface. It should be noted that the bracketed term on the right side of Eq. (12) is the same as that appearing in the universal law of friction for an annular geometry, Eq. (2).

The left side of Eq. (12) can be written in the form

$$
\left(\frac{T_{w}-T_{B 1}}{T_{w}-T_{B}}\right) \frac{\left(T_{w}-T_{B}\right) \rho C_{p} \bar{u}}{q_{w}} \frac{u^{*}}{\bar{u}} \frac{u_{1}^{*}}{u^{*}}
$$

which is equivalent to the expression

$$
\left(\frac{T_{w}-T_{B}}{T_{w}-T_{B}}\right) \frac{\sqrt{f / 2} u_{1}^{*}}{S t u^{*}},
$$

where $f$ and $S t$ are the friction factor and Stanton number for the overall annulus. The quantities $f$ and St were directly determined from the experimental data, that is, no transformation was involved. The form of Eq. (15) is convenient because the ratio of friction velocities is easily evaluated using the relation ${ }^{2}$

$$
\frac{u_{1}^{*}}{u^{*}}=\left(\frac{\beta-\alpha^{2}}{\alpha(1-\alpha)}\right)^{1 / 2} \cdot\left(\frac{\rho}{\rho_{1}}\right)^{1 / 2}
$$

The parameter $\alpha$ in Eq. (16) is the radius ratio* for the annular geometry, while $\beta$ represents the ratio of the radius of the surface of zero shear to the radius of the smooth outer tube in which the rough rod is centered, and was calculated by the Dalle Donne-Meyer transformation. ${ }^{6}$ The density ratio term of Eq. (16) was assumed sufficiently close to unity to be neglected.

* This is the ratio of the volumetric radius of the rough rod to the radius of the inner wall of the smooth tube and is equal to $0.392,0.490$, and 0.599 for the three annular geometries used in this experiment. 
The value of the term on the left side of Eq. (12) was calculated for each heated set of experimental values in this analysis by performing the multiplication of the three terms as indicated in Eq. (15). The experimental results for each set of values are given in appendix $C$.

The parameters $A_{H}$ and $G\left(h^{+}\right)$of Eq. (12) are properties of the rough surface* and were determined for the CFTL rod in this experiment. Since the friction factor $f_{1}$ is constant in fully rough flow and the Stanton number $\mathrm{St}_{1}$ monotonically decreases as $\mathrm{h}^{+}$increases in this region ${ }^{2}$. Eq. (12) shows that $\mathrm{G}\left(\mathrm{h}^{+}\right)$ must monotonically increase with $\mathrm{h}^{+}$in fully rough flow. Conversely, in the transition zone both $\mathrm{f}_{\mathrm{l}}$ and $\mathrm{St}_{1}$ increase with $\mathrm{h}^{+}$so $\mathrm{G}\left(\mathrm{h}^{+}\right)$will be relatively constant. These considerations show that the dependence of $\mathrm{G}\left(\mathrm{h}^{+}\right)$upon the roughness Reynolds number is markedly different from the parameter $\mathrm{R}\left(\mathrm{h}^{+}\right)$of the friction law, Eq. (2).

The graphical method used for determination of the slope $A_{H}$ and intercept $G\left(h^{+}\right)$of Eq. (12) is by construction of straight lines connecting the points representing the flows in the differing annular geometries used in the experiment. Since the wall intercept $G\left(h^{+}\right)$is a function of the roughness Reynolds number, care was taken to ensure that each set of connected points represents results obtained at the same value of $\mathrm{h}^{+}$.

The method used for determination of $\mathrm{A}_{\mathrm{H}}$ and $\mathrm{G}\left(\mathrm{h}^{+}\right)$is similar to that employed for determination of the analogous quantities for the friction law in the transition region. However, there is an important additional restriction on the utilization of the graphical procedure; this is due to the dependence of the coolant physical properties upon temperature. Since the experimentally determined friction factors and Stanton numbers are affected by the variation of coolant temperature across the annular gap, the experimental results used for the purpose of comparison in the different annular geometries should be obtained at approximately the same coolant bulk temperatures and wall-to-bulk temperature ratios $\left(T_{W} / T_{B}\right)$. Two sets of comparable results were found for the CFTL rod heated flow experiments; each is characterized by the (controlled) maximum rod wall temperature. The maximum wall temperature $\left(T_{W M}\right)$ and the range of wall-to-bulk temperature ratios for both sets of comparable results are listed in Table 3

\begin{tabular}{|c|c|c|}
\hline TWM & $\begin{array}{c}\text { Annular gap } \mathrm{Y}_{\mathrm{T}} \\
(\mathrm{mm})\end{array}$ & $T_{W} / T_{B}$ \\
\hline \multirow{3}{*}{$150^{\circ} \mathrm{C}$} & 6.08 & $1.31-1.34$ \\
\hline & 4.08 & $1.25-1.29$ \\
\hline & 2.62 & $1.17-1.21$ \\
\hline \multirow{3}{*}{$350^{\circ} \mathrm{C}$} & 6.08 & $1.71-1.79$ \\
\hline & 4.08 & $1.56-1.63$ \\
\hline & 2.62 & $1.35-1.43$ \\
\hline
\end{tabular}

To find the slope $\mathrm{A}_{\mathrm{H}}$ and the intercept $\mathrm{G}\left(\mathrm{h}^{+}\right)$of $\mathrm{Eq}$. (12) graphically, values of the ordinate [on the left side of Eq. (12)] were plotted as a function of the corresponding values of the bracketed abcissa term on the right side. The corresponding plotted values represent flows within the different annular fluids. ${ }^{1}$

*'The parameter $\mathrm{G}\left(\mathrm{h}^{+}\right)$is also a function of the Prandtl number and would therefore differ for the same roughness in different 
geometries at the same roughness Reynolds number so that the associated values of the wall intercept $\mathrm{G}\left(\mathrm{h}^{+}\right)$are the same.

\section{RESULTS FOR $\mathrm{T}_{W M}=150^{\circ} \mathrm{C}$}

The set of curves for analysis of the heat flow results for a maximum rod wall temperature of $150^{\circ} \mathrm{C}$ are shown in Figs. 7-9. The ordinate terms obtained for the tests in the three different annular geometries are plotted as functions of the roughness Reynolds number in Fig. 7. The two straight-line approximations on this figure are least-squares fits to the plotted points representing flow in the 20 -mm and 13-mm annular geometries, over the ranges indicated; a fit to the limited number of values available for flow in the 16-mm geometry was not attempted.

Values for the ordinate [on the left side of Eq. (12)] were obtained at the same value of $h^{+}$for flow in the two different annular geometries by using the linear least-squares fitted equations indicated on Fig. 7. The abcissa values are shown in Fig. 8. The ordinate values from Fig. 7 and the abcissa values from Fig. 8 are plotted in the form of Eq. (12) at several values of $h^{+}$in Fig. 9.

The slopes and ordinate intercepts of the straight lines shown on Fig. 9 are the values of $A_{H}$ and $\mathrm{G}\left(\mathrm{h}^{+}\right)$for Eq. (12) for the CFTL rod at the indicated roughness Reynolds numbers for the tests at a maximum wall temperature of $150^{\circ} \mathrm{C}$. These quantities are listed as functions of $\mathrm{h}^{+}$in Table 4 .

\begin{tabular}{ccc}
$\begin{array}{c}\text { Table 4. Slopes } \\
\text { ordinate intercepts for } \\
\text { the straight lines } \\
\text { of Fig. } 9\end{array}$ \\
\hline \multicolumn{3}{c}{. } \\
\hline $\mathrm{h}^{+}$ & $\mathrm{A}_{\mathrm{H}}$ & $\mathrm{G}\left(\mathrm{h}^{+}\right)$ \\
\hline 20 & 0.762 & 14.665 \\
30 & 0.831 & 15.117 \\
40 & 0.878 & 15.456 \\
50 & 0.914 & 15.726 \\
60 & 0.945 & 15.952 \\
70 & 0.971 & 16.146 \\
80 & 0.992 & 16.319 \\
90 & 1.012 & 16.472 \\
100 & 1.028 & 16.616 \\
\hline
\end{tabular}

The slope $A_{H}$ can be expressed as a function of the roughness Reynolds number $\mathrm{h}^{+}$by the relation

$$
\mathrm{A}_{\mathrm{H}}=0.645+6.9 \times 10^{-3} \mathrm{~h}^{+}-3.1 \times 10^{-5}\left(\mathrm{~h}^{+}\right)^{2} \text {. }
$$

The values of $\mathrm{G}\left(\mathrm{h}^{+}\right)$calculated from the experimental results in the CFTL rod heated tests with a maximum wall temperature of $150^{\circ} \mathrm{C}$ are shown plotted as a function of $\mathrm{h}^{+}$in Fig. 10. These points were calculated using Eq. (12) with experimentally determined values for the term $\sqrt{\mathrm{f}_{1} / 2} / \mathrm{St}_{1}$ and the abcissa term of Eq. (4), and values of $A_{H}$ as determined by Eq. (17). The plotted values are limited to those derived from the results of the heated tests for which the heat balance error* was no more than five percent.

*The heat balance error for each of the heated test runs is included in the calculated results tabulated in Appendix C. 
ORNL-DWG 81-8721 ETD

CFTL ROD

HEATED TESTS

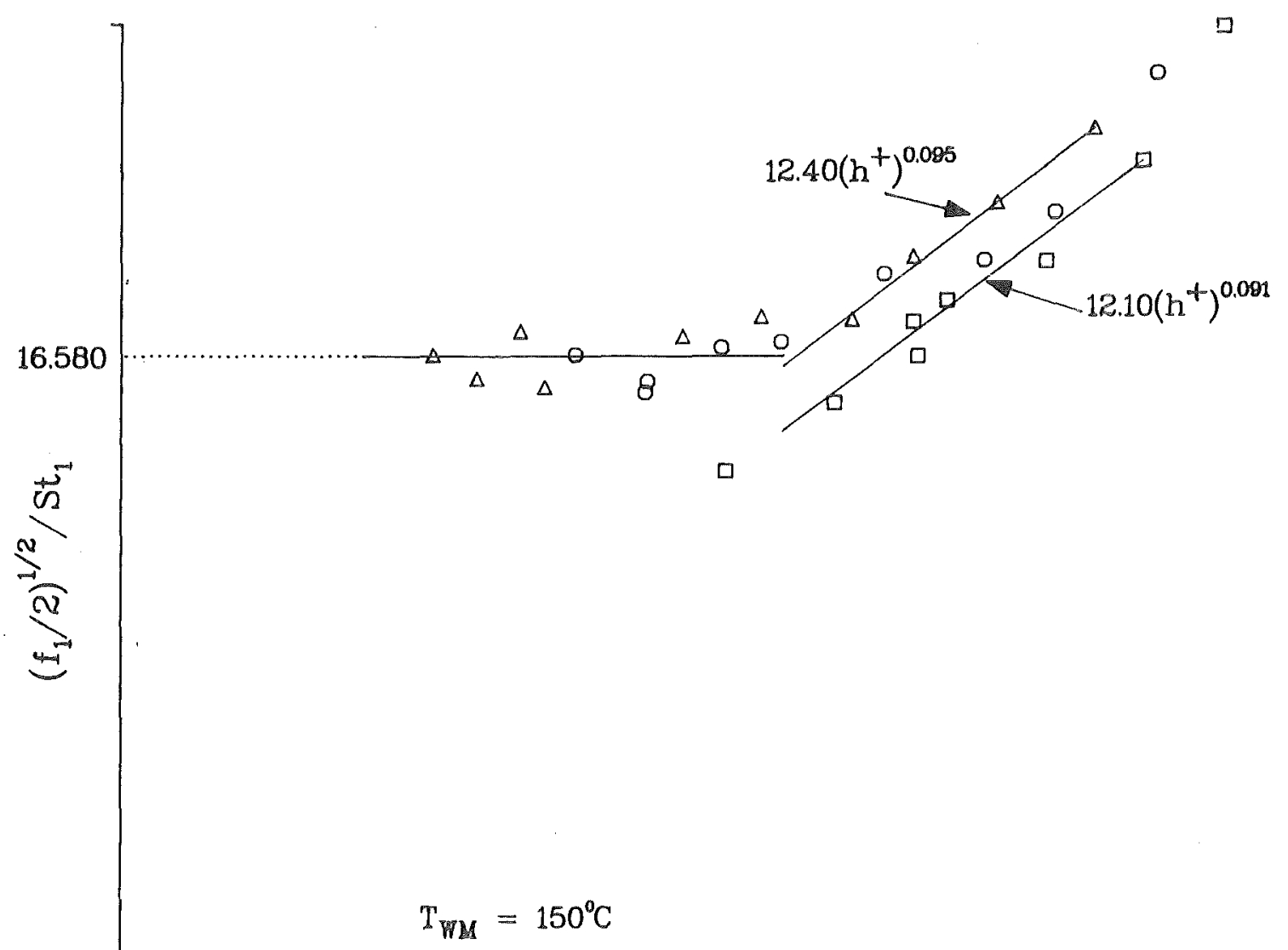

$\Delta \quad 1.31<\mathrm{T}_{W} / \mathrm{T}_{\mathrm{B}}<1.34$ SHROUD 20

$0 \quad 1.25<\mathrm{T}_{\mathrm{W}} / \mathrm{T}_{\mathrm{B}}<1.29$ SHROUD 16

- $1.17<\mathrm{T}_{\mathrm{T}} / \mathrm{T}_{\mathrm{B}}<1.21$ SHROUD 13

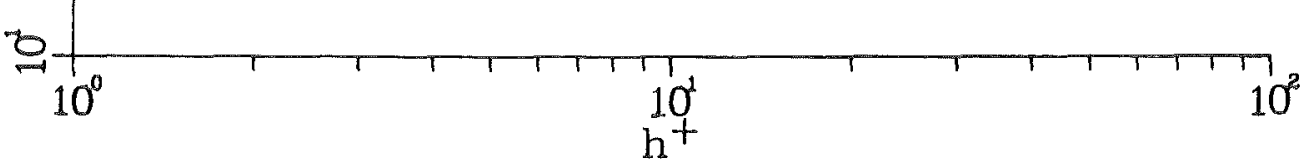

Fig. 7. Variation of ordinate values with roughness Reynolds number for flow with heat transfer. 


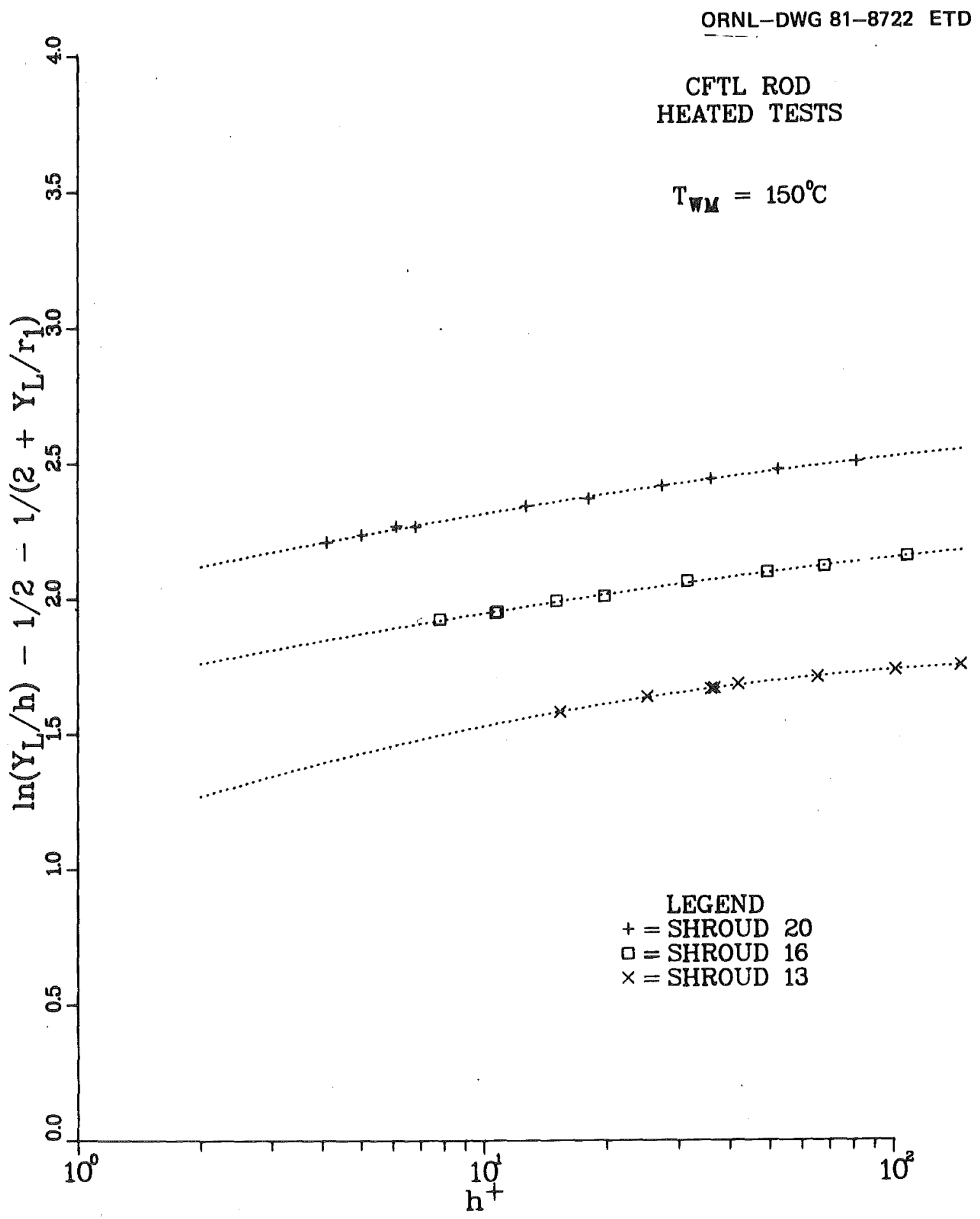

Fig. 8. Variation of abscissa values with roughness Reynolds number in the transition zone. 


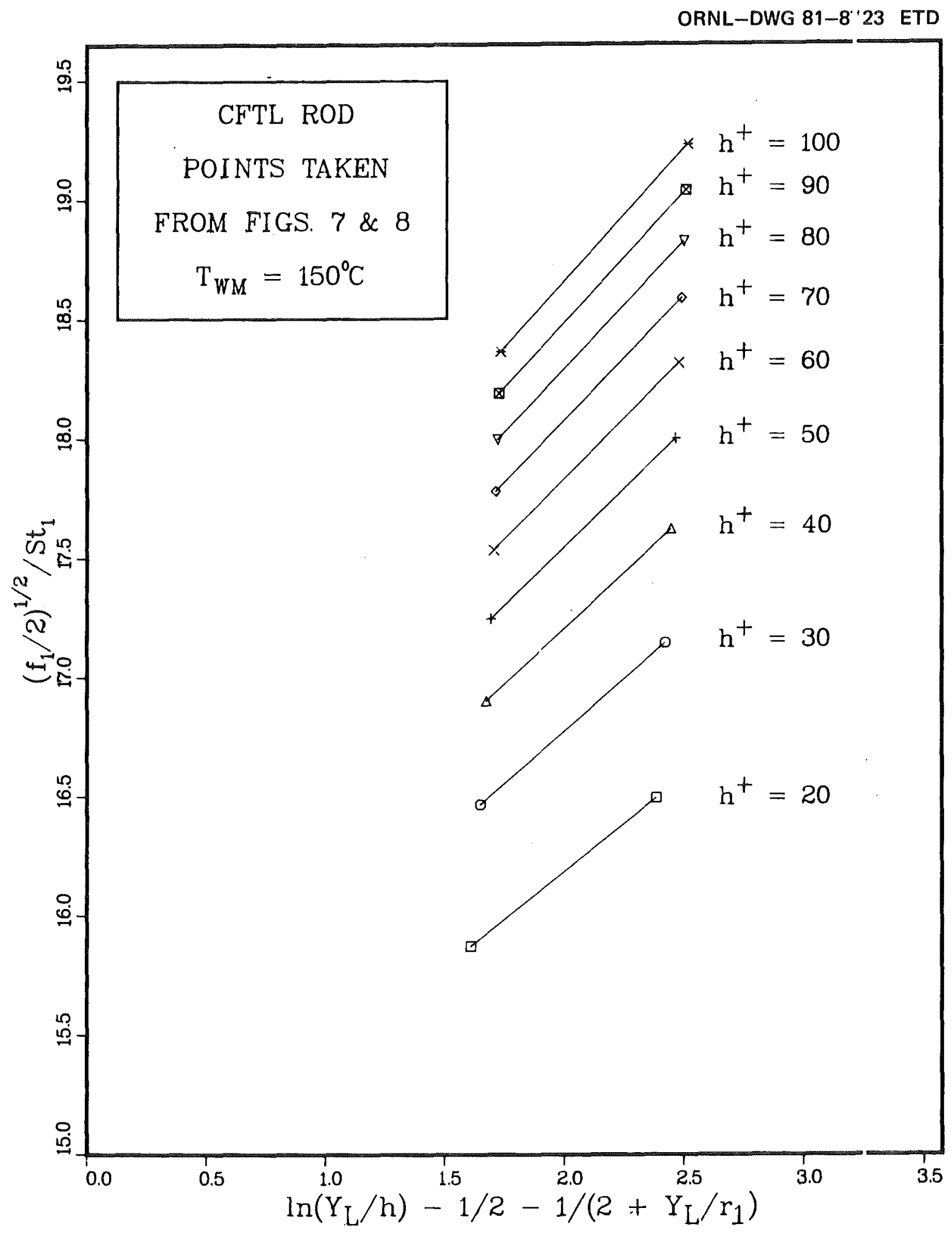

Fig. 9. Universal law of heat transfer for CFTL rod. 


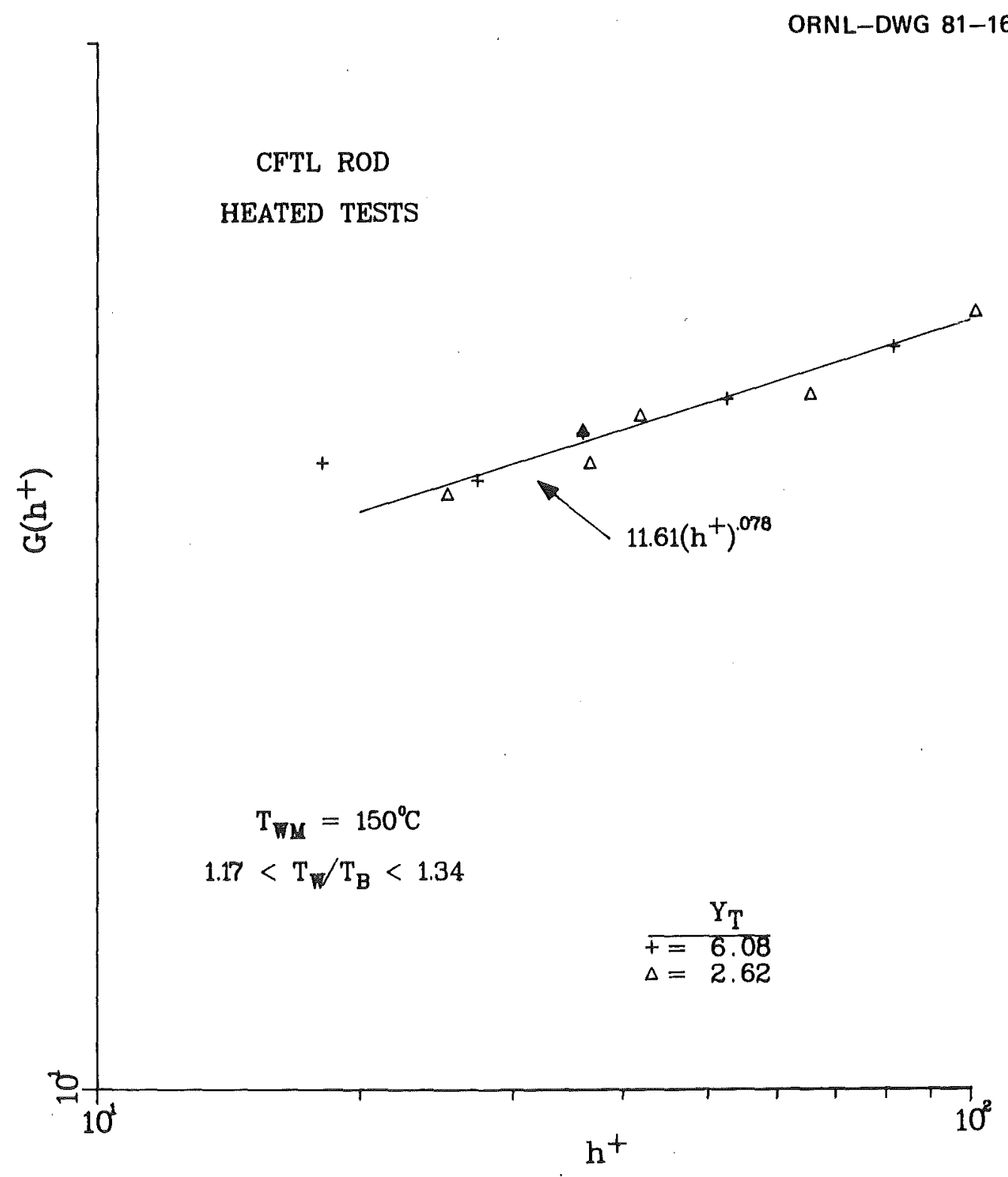

Fig. 10. Correlation for $\mathrm{G}\left(\mathrm{h}^{+}\right)$using slopes determined graphically for the CFTL rod. 
For values of $\mathrm{h}^{+}$less than 20 , the flow is in the transition zone, and the value of the ordinate term is approximately constant and independent of the annular geometry as shown in Fig. 7. Accorcingly, these experimental results show that once the friction factor has been determined, the Stanton number for use in CFTL analyses of transitional zone flow at $\mathrm{T}_{\mathrm{WM}}$ of about $150^{\circ} \mathrm{C}$ can be calculated using the relation

$$
\left(f_{1} / 2\right)^{1 / 2} / S_{t_{1}}=16.580 .
$$

This relation should give satisfactory results over the range of roughness Reynolds numbers fro $n$ the onset of turbulent flow, about $h^{+}=3$, to the beginning of the fully rough regime at about $h^{+}=20$.

\section{RESULTS FOR T $\mathrm{WM}_{\mathrm{W}}=350^{\circ} \mathrm{C}$}

The curves for the analysis of the experimental results for test runs with heated flow at a maximum rod wall temperature of $350^{\circ} \mathrm{C}$ are shown in Figs. 11-13. The ordinate terms obtained for the tests in the three different annular geometries are plotted as functions of the roughness Reynolds number in Fig. 11. The three straight-line approximations on the right side of this figure are least-squares fits $t 0$ the plotted points representing flow at values of $\mathrm{h}^{+}$greater than about 9.0 in each of the annular geometries used in the experiment.

Values for the ordinate [on the left side of Eq. (12)] were obtained at the same value of $\mathrm{h}^{+}$for flow in the three different annular geometries by using the linear least-squares fit equations indicated on the right side of Fig. 11. The abcissa values are shown in Fig. 12.* The ordinate values from Fig. 11 and the abcissa values from Fig. 12 are plotted in form of Eq. (12) at several values of $\mathrm{h}^{+}$in Fig. 13.

As can be seen on Figs. 11 and 13, the plotted results for the flow in shroud 13 do not conform to the expected trend indicated by the results for the 16 and $20-\mathrm{mm}$ shrouds. This may be due to the m.tch larger spread of wall-to-bulk temperature ratios for the tests at a maximum rod wall temperature of $350^{\circ} \mathrm{C} \dagger$, or it may be due to an effect of undetected rod bowing at these higher temperatures in this smallest shroud. These anomalous results for the heated flow in shroud 13 at a maximum rod wall temperature of $350^{\circ} \mathrm{C}$ were not considered further in the analysis.

With the results for the flow in shroud 13 neglected, the slopes and ordinate intercepts of the straight lines connecting the points for flow in shrouds 16 and 20 are assumed to be the values of $A_{11}$ and $\mathrm{G}\left(\mathrm{h}^{+}\right)$for use in Eq. (12) for the tests at a maximum wall temperature of $350^{\circ} \mathrm{C}$. These quantities are listed as functions of $\mathrm{h}^{+}$in Table 5 .

The relation between the slope $A$ and the roughness Reynolds number $\mathrm{h}^{+}$for the heated tests $\mathrm{a}: \mathrm{a}$ maximum wall temperature of $350 \mathrm{C}$ as listed in Table 5 is well approximated by

$$
\mathrm{A}_{\mathrm{H}}=1.489-2.462 \times 10^{-2} \mathrm{~h}^{+}+1.109 \times 10^{-4}\left(\mathrm{~h}^{+}\right)^{2} .
$$

The values of $\mathrm{G}\left(\mathrm{h}^{+}\right)$calculated from the experimental results in the CFTL rod heated tests with a maximum wall temperature of $350^{\circ} \mathrm{C}$ are shown plotted as a function of ${ }^{+}$in Fig. 14. These points were calculated using Eq. (12) with experimentally determined values for the term $\sqrt{f_{1} / 2} / S_{1}$ and the abcissa term of Eq. (4), and values of $A_{H}$ as determined by Eq. (19). As before, the plotted values are limited to

\footnotetext{
*It is interesting to note that a comparison of Figs. 3, 8, and 12 indicates that there is no effect of temperature upon the abcissa values.

$+$ would be necessary to heat the inlet flow to the test section foir test in the larger annular geometries in order to reduce this spread.
} 
ORNL-DWG 81-16126 ETD

CFTL ROD

HEATED TESTS

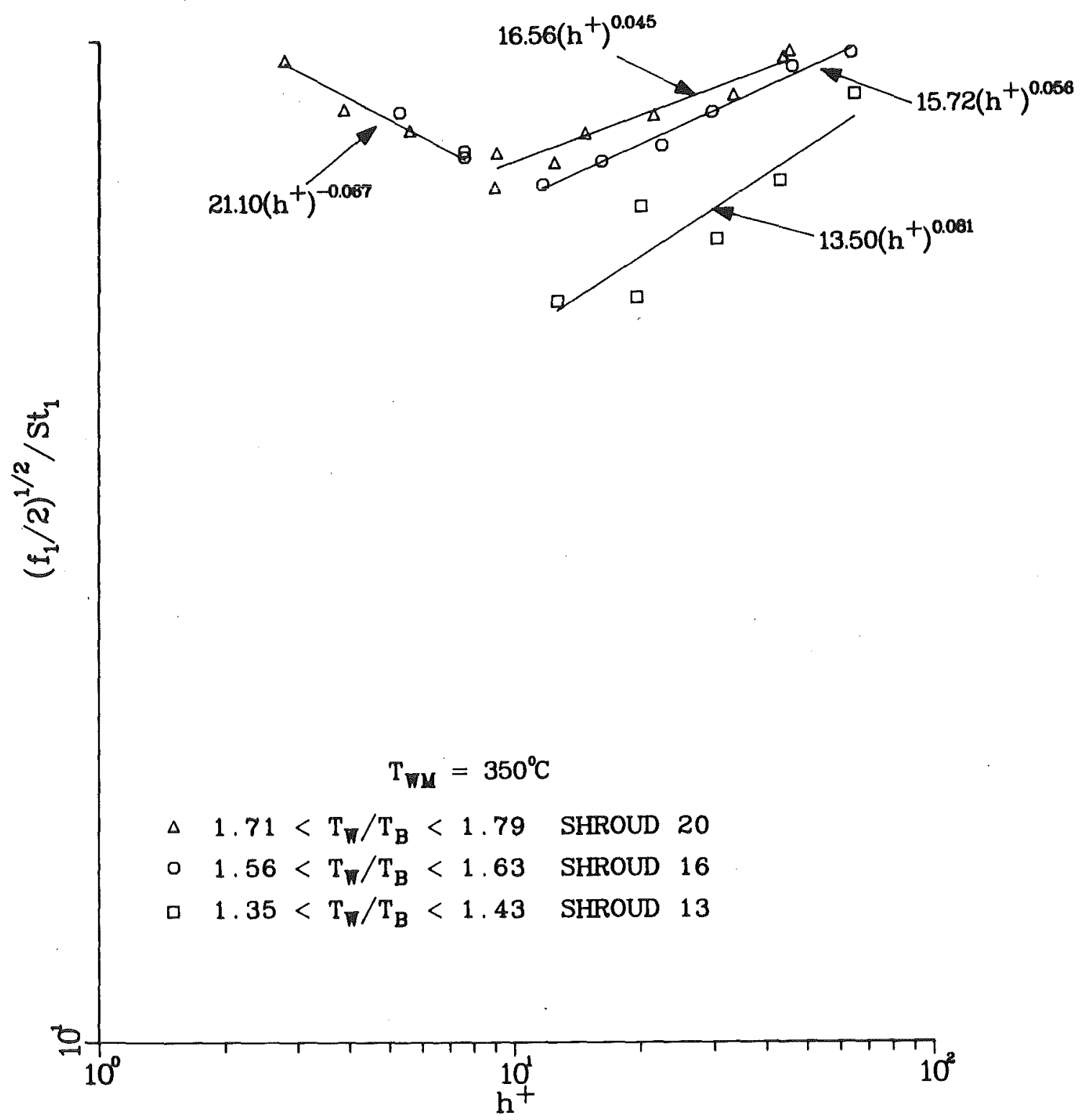

Fig. 11. Variation of ordinate values with roughness Reynolds number for flow with heat transfer. 


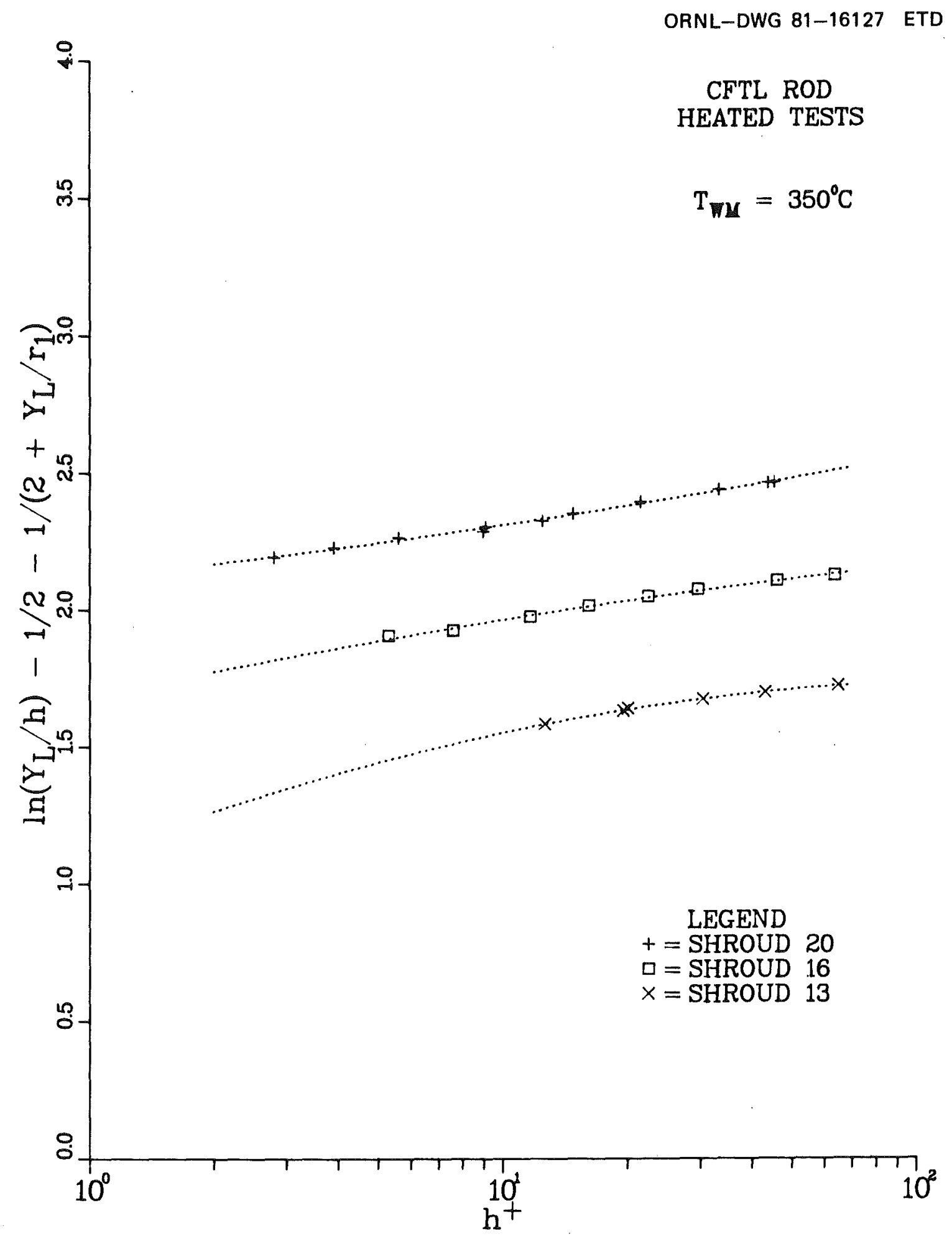

Fig. 12. Variation of abscissa values with roughness Reynolds number in the transition zone. 


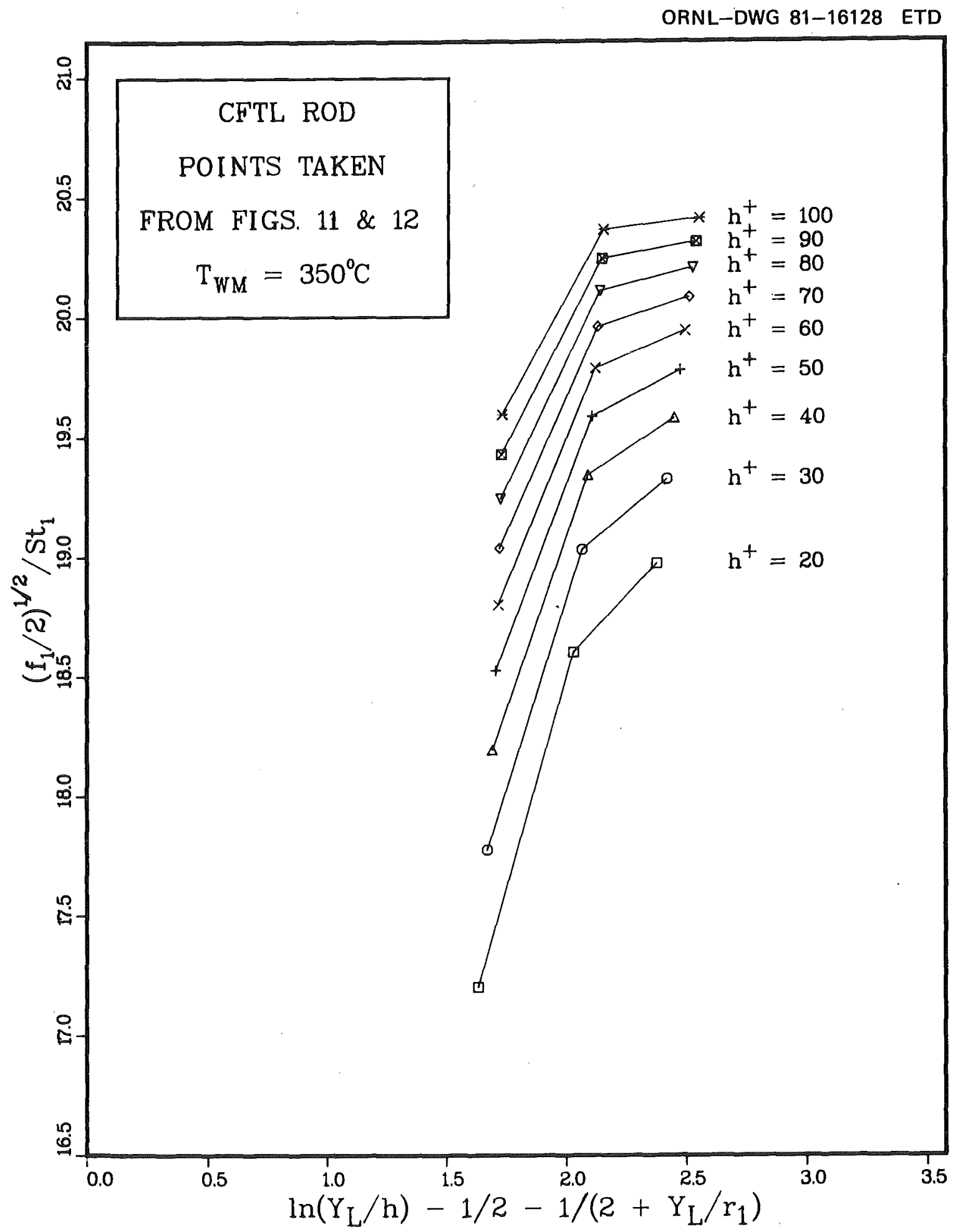

Fig. 13. Universal law of heat transfer for CFTL rod. 


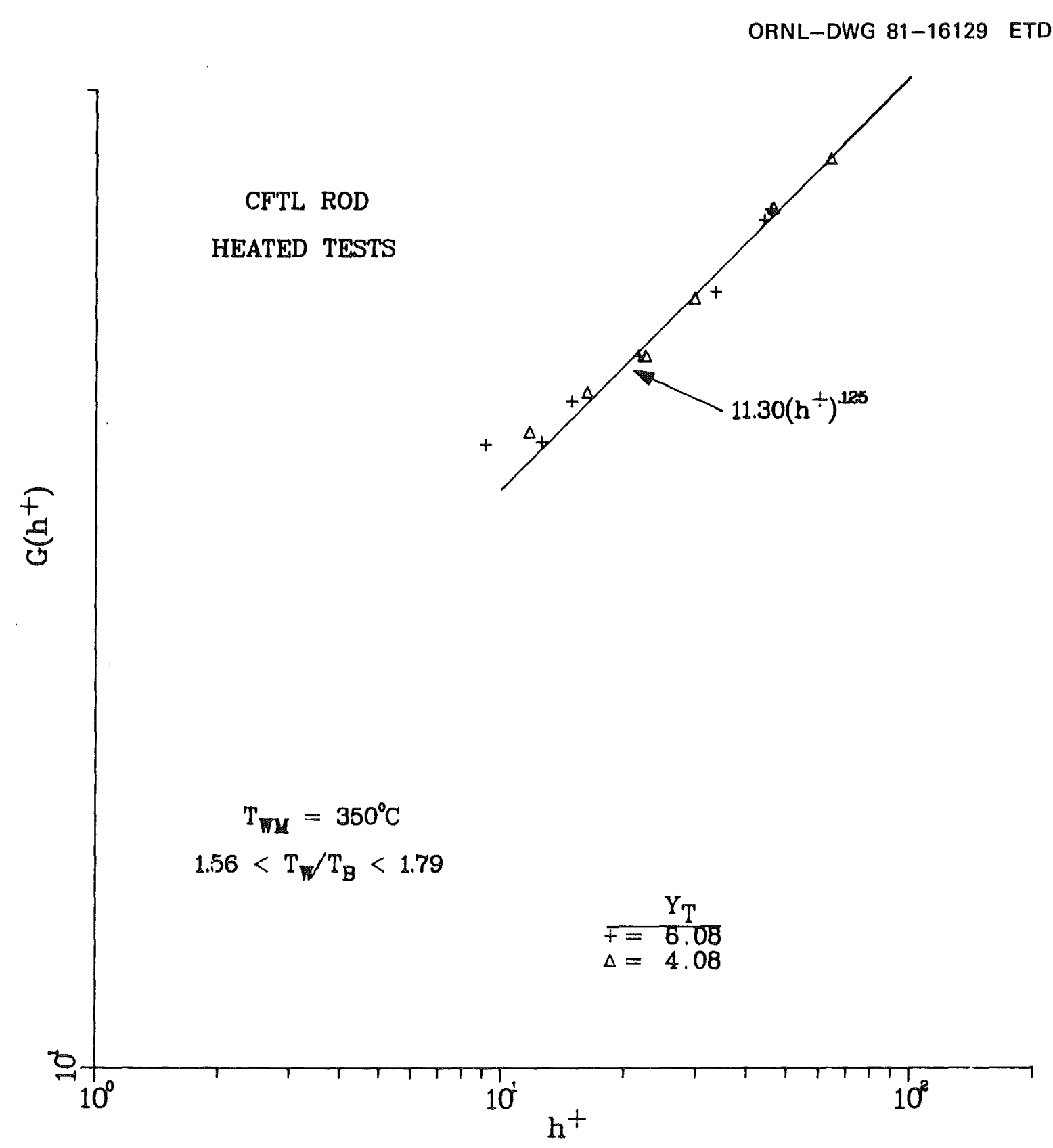

Fig. 14. Correlation for $\mathrm{G}\left(\mathrm{h}^{\dagger}\right)$ using slopes determined graphically for the CFTL rod. 
Table 5. Slopes $A_{H}$ and intercepts for

the straight lines connecting points

representing the $16-\mathrm{mm}$ and

20-mm annular geometries

of Fig. 13

\begin{tabular}{rcc}
\hline $\mathrm{h}^{+}$ & $\mathrm{A}_{\mathrm{H}}$ & $\mathrm{G}\left(\mathrm{h}^{+}\right)$ \\
\hline 20 & 1.067 & 16.438 \\
30 & 0.833 & 17.312 \\
40 & 0.660 & 17.962 \\
50 & 0.524 & 18.482 \\
60 & 0.417 & 18.903 \\
70 & 0.325 & 19.266 \\
80 & 0.245 & 19.585 \\
90 & 0.178 & 19.861 \\
100 & 0.118 & 20.110 \\
\hline
\end{tabular}

those derived from the results of the heated tests for which the heat balance error was no more than five percent.

\section{CONCLUSIONS}

Correlations have been established for use in the calculation of both pressure drop and heat transfer for flow in the various channels of the proposed CFTL bundle. The nature and use of these correlations will be summarized in this section.

For fully rough flow, the friction factor under both heated and isothermal conditions can be calculated by use of Eq. (2) with the constant values

$$
A=2.96
$$

and

$$
\mathrm{R}\left(\mathrm{h}^{+}\right)=4.45 \text {. }
$$

The development of these values from the experimental results is shown in Fig. 1.

With the friction factor known, the Stanton number in fully rough flow can be determined by use of Eq. (12). The values of $A_{H}$ and $G\left(h^{+}\right)$for use in this equation depend upon the temperatures and temperature differences associated with the flow, which can be characterized by the maximum rod wall temperature $\mathrm{T}_{\mathrm{WM}}$. For a $\mathrm{T}_{\mathrm{WM}}$ of $150^{\circ} \mathrm{C}, \mathrm{A}_{\mathrm{H}}$ is given by Eq. (17) while $\mathrm{G}\left(\mathrm{h}^{+}\right)$can be read from Fig. 10 or calculated from the relation

$$
\mathrm{G}\left(\mathrm{h}^{+}\right)=11.61\left(\mathrm{~h}^{+}\right)^{0.078} \text {. }
$$

For a $\mathrm{T}_{\mathrm{WM}}$ of $350^{\circ} \mathrm{C}, \mathrm{A}_{\mathrm{H}}$ is given by Eq. (19) and $\mathrm{G}\left(\mathrm{h}^{+}\right)$can be taken from Fig. 14 or calculated using the relation

$$
\mathrm{G}\left(\mathrm{h}^{+}\right)=11.30\left(\mathrm{~h}^{+}\right)^{0.0125} \text {. }
$$

For conditions characterized by maximum rod wall temperatures other than the 150 and $350^{\circ} \mathrm{C}$ employed in this experiment, it is recommended that the results of these correlations be used in the process of linear interpolation or extrapolation as necessary to calculate values appropriate to the desired temperatures. 
In this work, the limits of the transition from hydraulically smooth to fully rough turbulent flow have been well established for the CFTL roughness in terms of the roughness Reynolds number $\left(\mathrm{h}^{+}\right)$. For flow channels with physical dimensions near those of the proposed CFTL bundle, the transition zone begins at an $\mathrm{h}^{+}$value at about 4.0 and continues to an $\mathrm{h}^{+}$value of about 20.0 as shown o. Fig. 2.

For flow in the transition zone, the friction factor can again be calculated through use of $E_{\uparrow}$. (2). In this flow regime, the parameter $A$ was found to remain constant at the same value as for fully roligh flow (Eq. 20). However, the parameter $\mathrm{R}\left(\mathrm{h}^{+}\right)$was found to be a function of the roughness Reynolds number and can be calculated using Eq. (9).

With the friction factor known, the Stanton number in the transition zone can be easily deturmined through use of simple expressions for the term

$$
\sqrt{\mathrm{f}_{1} / 2} / \mathrm{St}_{1}
$$

which is independent of velocity profile width in this flow regime. As shown in Fig. (7), a value of 16.58 is a ppropriate for transitional zone flow at a $\mathrm{T}_{W M}$ of $150^{\circ} \mathrm{C}$. For flow at a $\mathrm{T}_{W M}$ of $350^{\circ} \mathrm{C}$, this terin is well represented by the relation

$$
\sqrt{f_{1} / 2} / \mathrm{St}_{1}=21.10\left(\mathrm{~h}^{+}\right)^{-0.067}
$$

as shown in Fig. 11.

\section{SUMMARY}

Several different universal velocity profile widths would exist simultaneously in the different channels within the roughened portion of the CFTL bundle design. A successful analysis of the distribution of these channel flows depends upon prior determination of the behavior of the riction factor and Stanton number as functions of the velocity profile width for the particular CFTL roughness.

In this report, the results of an experiment performed at Kernforschungszentrum Karlsiuhe to determine the friction factor and Stanton number behavior characteristics of a prototype CFTL. roughened rod are presented. The methods described in an earlier work ${ }^{\prime}$ are implemented to convert the experimental results into correlations for the roughness friction factor parameters $A$ and $R\left(h^{+}\right)$and the roughness heat transfer parameters $A_{H}$ and $G\left(h^{+}\right)$.

The dependence of these four roughness parameters upon the roughness Reynolds number $\mathrm{h}^{+}$was experimentally determined by testing a single prototypic CFTL roughened rod in a series of three annular geometries. The three test annular geometries were formed by placing the roughened CF IL rod successively at the center of each of three smooth outer shroud tubes of different diameter. The: Dalle Donne-Meyer transformation ${ }^{6}$ was used for calculation of both the location of the surface of zero shear in the flow and the friction factor associated with the rough surface.

The results of this experimental and analytical effort are conclusive in establishing the roughness parameters for determination of the friction factors in the various channels of the CFTL bundle design, both for fully rough and transitional zone flow. The test results indicate that the isothermal $f$ iction factor correlations are valid for heated flow as well as for isothermal flow, for flows in small a inular geometries such as that associated with the bundle dimensions of the CFTL.

The experimental results for the determination of the heat transfer parameters a re less conclusive. Heat transfer correlations for the determination of Stanton number are recommended for flows past 
rods of the CFTL design with maximum rod wall temperatures of $150^{\circ} \mathrm{C}$ and $350^{\circ} \mathrm{C}$. These correlations can be used for interpolation or extrapolation as necessary to determine the Stanton number for flows within the CFTL bundle at different maximum rod wall temperatures.

\section{NOMENCLATURE}

A

$\mathrm{A}_{\mathrm{H}}$

$\mathrm{C}_{1}, \mathrm{C}_{2}, \mathrm{C}_{3}$

$\mathrm{C}_{4}, \mathrm{C}_{5}, \mathrm{C}_{6}$

$\mathrm{C}_{\mathrm{p}}$

D

f

$\mathrm{G}\left(\mathrm{h}^{+}\right)$

h

$\mathrm{h}^{+}$

$\mathrm{q}_{\mathrm{w}}$

r

$\operatorname{Re}$

$\mathrm{R}\left(\mathrm{h}^{+}\right)$

$\mathrm{St}$

$\mathrm{T}_{\mathrm{B}}$

$\mathrm{T}_{\mathrm{w}}$

$T_{\mathrm{mm}}$

$\overline{\mathrm{u}}$

$\mathrm{u}^{*}$

$\overline{\mathrm{u}}^{+}$

$\mathrm{Y}_{\mathrm{L}}$

$\mathrm{Y}_{\mathrm{T}}$
Slope of Eq. (2); mathematically equivalent to slope of dimensionless velocity profile

Slope of Eq. (12); mathematically equivalent to slope of dimensionless temperature profile

Constants in Eq. (6)

Constants in Eq. (7)

Specific heat at constant pressure

Equivalent diameter

Fanning friction factor

Heat transfer roughness parameter for a particular fluid

Height of roughness element

Roughness Reynolds number $\left(=\frac{\mathrm{hu}^{*}}{v}\right)$ based on the viscosity at the temperature at the wall

Heat flux at the wall

Radius

Reynolds number

Roughness parameter for frictional pressure loss

Stanton number

Bulk coolant temperature

Temperature at the wall

Maximum measured temperature along the rough wall

Spacially averaged axial velocity

Friction velocity $\left(=\sqrt{\tau_{\mathrm{w}} / \rho}\right)$

Average value of dimensionless velocity $\left(=\bar{u} / u^{*}\right)$

Velocity profile width, from volumetric surface of rough wall to surface of zero shear

Annular gap, distance in annular test geometry from volumetric surface of rough wall to smooth surface 


\section{Greek Symbols}

$\begin{array}{ll}\alpha & \text { Radius ratio of annulus }\left(=r_{1} / r_{2}\right) \\ \beta & \begin{array}{l}\text { Ratio of radius of surface of zero shear in annular test geometry to radius of } \\ \text { smooth tube wall }\left(=r_{0} / r_{2}\right)\end{array} \\ \rho & \text { Density } \\ \tau & \text { Shear stress at the wall } \\ v & \text { Kinematic viscosity }\end{array}$

\section{Subscripts}

Pertaining to the rough surface, or to the zone of flow in annular geometry between the rough surface and the surface of zero shear

Pertaining to the smooth tube wall in annular test geometry

\section{REFERENCES}

1. S. A. Hodge, "Determination of Coefficients for the Universal Laws of Friction and Heat Transfer for CFTL Calculations," ORNL/TM-7418 (1980).

2. S. A. Hodge, J. P. Sanders, and D. E. Klein, "Determination of Friction Factors and Heat Transfer Coefficients for Flow Past Articifically Roughened Surfaces," ORNL-5599 (1979).

3. J. Nikuradse, "Laws of Flow in Rough Pipes," NACA TM 1292 (1950).

4. S. A. Hodge, J. P. Sanders, and D. E. Klein, "Slope and Intercept of the Dimensionless Velocity Profile for Articifically Roughened Surfaces," Int. J. Heat Mass Transfer, 23, 135-140 (1980).

5. L. Meyer and L. Vogel, "The Velocity Distribution and Pressure Loss of Artificial Roughnesses with Sharp and Rounded Edges," KfK 2885 (1979).

6. M. Dalle Donne and L. Meyer, "Turbulent Convective Heat Transfer from Rough Surfaces with Two-Dimensional Rectangular Ribs," Int. J. Heat Mass Transfer, 20, 583-620 (1977).

7. M. Dalle Donne, "Heat Transfer from Rough Surfaces," Report KfK 2397, EUR 5506d (1977) (in German).

8. L. Meyer, "Heat Transfer and Pressure Drop at Single Rods with Three-Dimensional Roughnesses: Large Scale Tests," Report KfK 3164 (1981).

9. M. Dalle Donne and L. Meyer, "Heat Transfer and Pressure Drop at Single Rods Roughened with Three-Dimensional Ribs," OCED-NEA 6th GCFR Heat Transfer Specialists Meeting, Berkeley, England (1980).

10. L. Meyer, "Friction and Heat Transfer Correlations for the Roughness of the BR2 Calibration Element," Report KfK 2986 (1980).

11. L. Meyer and K. Rehme, "Heat Transfer and Pressure Drop Measurements with Roughened Single Pins Cooled by Various Gases, Report KfK 2980 (1980). 
Appendix A

PHOTOMICROGRAPH OF CFTI CLADDING SURFACE 

MC - IC - O

\section{INTRA-LABORATORY CORRESPONDENCE \\ OAK RIDGE NATIONAL LABORATORY \\ March 4, 1981}

To: John P. Sanders

Building 9108, Mai1 Stop 2, Room 203, Y-12

From:

R. J. Gray K)

Subject: Photomicrograph $75 x$, Longitudinal Profile of Centerless Ground, Type 316 SS Tubing.

Enclosed are 6 prints of the subject examination. You expressed a primary interest in the profile of the grinding operation. The microstructure shows some mechanical twinning across the entire tube wa11. This twinning undoubtedly was produced in a cold working step-probably during a drawing or straightening operation. The grinding operation did not produce localized cold working at the surface. The absence of cold working indicates a careful grinding procedure.

\section{RJG/b1h}

Enclosure

Etchant: Electrolyte $40 \% \mathrm{HNO}_{3}$ in water, $0.01 \mathrm{amps} / \mathrm{CM}^{2}$

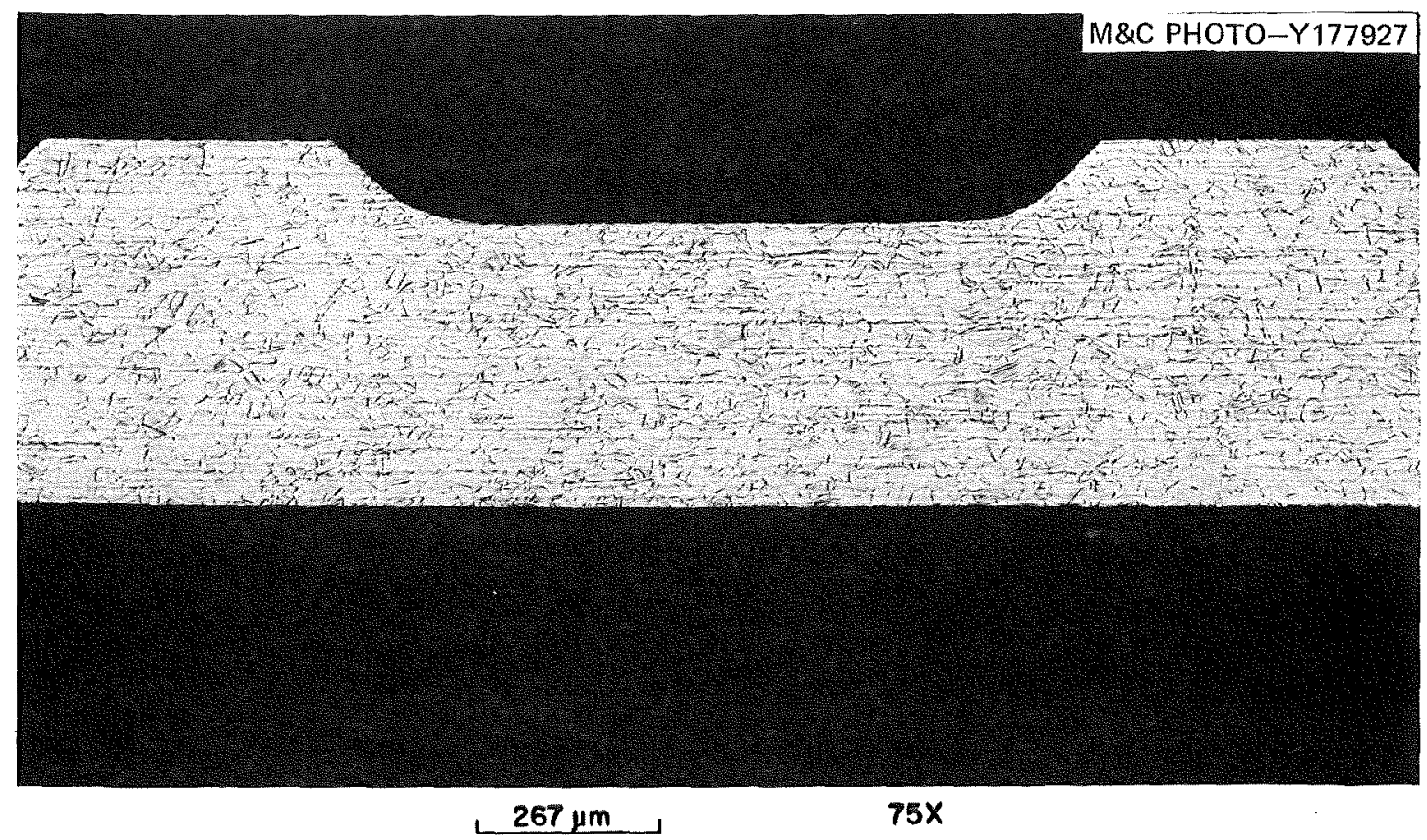





\section{Appendix B}

\section{EXPERIMENTAL APPARATUS AND PROCEDURE}

The experiment was performed in an air test rig at Kernforschungszentrum Karlsruhe (KfK). The apparatus and the experimental techniques were similar to those previously used in both large scale and small scale tests. ${ }^{7-11}$

A schematic diagram of the experimental apparatus used for the CFTL rod experiment is shown in Fig. B-1. Air is circulated through this open loop by a compressor; the pressure pulsations are damped in a large hold up tank. An air drier reduces the humidity of the air. Air flow is measured by one of four available orifice flowmeters placed in parallel and calibrated over various ranges of mass flow. After passing through the annular test section, the air is released through a silencer to the atmosphere. The apparatus is capable of a maximum mass flow of $90 \mathrm{grams} / \mathrm{s}$, at a maximum pressure of five atmospheres.

The test series involved both the isothermal and hea ted axial flow of air past the roughened CFTL rod surface successively placed in three different annular geometries. The annular flow channels were each formed by placing the rough rod at the center of one of three smooth tubes of varying diameter. One smooth tube of $20-\mathrm{mm} \mathrm{I.D.} \mathrm{and} \mathrm{another} \mathrm{of} \mathrm{16-mm} \mathrm{I.D.} \mathrm{were} \mathrm{supplied} \mathrm{for} \mathrm{these} \mathrm{tests} \mathrm{by} \mathrm{KfK;} \mathrm{the}$ third smooth tube of 13.08-mm I.D. was supplied by ORNL and subsequently straightened and honed at KfK before use.

The pressure gradient along the test section was measured at eight static pressure taps spaced at 80 $\mathrm{mm}$ intervals along the surface of the smooth tube. The location of the static pressure taps and the placement of the 7.82-mm diameter CFTL rod within the smooth outer tube of 16-mm diameter are shown in Fig. B-2. The absolute and differential pressures were measured by five capacitance-type pressure transducers (MKS-Baratron) with an accuracy of better than $1 \%$ over the range from 1 to $10^{6}$ $\mathrm{Pa}$.

For the heated tests, temperatures were measured by sheathed Nickel-Chromium/Nickel-Alumel thermocouples. The CFTL rod wall temperature profile was measured by 14 thermocouples placed at 10 different axial locations along the rod; two thermocouples were placed on opposite sides of the rod at four locations so that any rod bowing would be indicated by a significant temperature difference. The outer surface of each smooth tube was insulated by a thick layer of Kerlane tape and the tube wall temperature was measured by 16 thermocouples placed at 8 axial locations. Three additional thermocouples were placed to measure the air bulk temperature in a mixing chamber at the test section outlet. The rod power, which can be varied from 0 to $13 \mathrm{~kW}$, was adjusted as necessary to keep the maximum rod wall temperature constant during each series of test runs at different mass flows.

The spacers located between the first and second and between the seventh and eighth pressure taps as shown on Fig. B-2 were used only for the tests in the 13-mm and the 16-mm smooth outer tubes. The purpose of these spacers was to avoid test inaccuracies introduced by rod bowing when there is a small clearance between the rod wall and the inner tube wall. The spacers consisted of three thin pieces of metal which were laser-beam welded directly to the rod surface. The spacer tips were insulated from the inner tube wall by a ceramic layer.

A heat balance was performed for all non-isothermal runs to compare the measured electrical input power to the rod with the thermal power calculated from the measured mass flow and air temperature increase. Only data for the runs in which the difference in the electrical and thermal powers was less than $6 \%$ were retained for further analyses. 


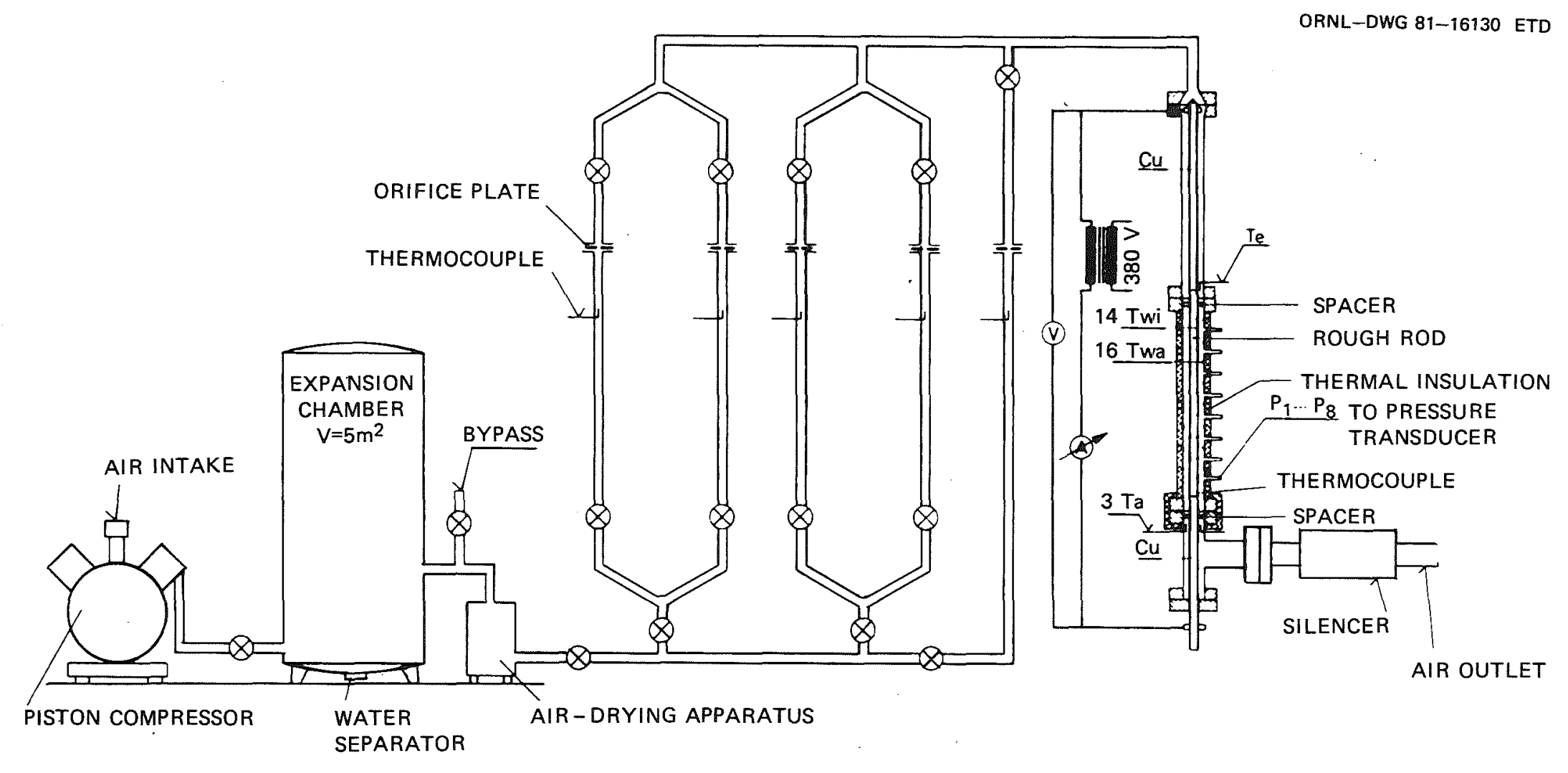

Fig. B-1. Apparatus used for the KfK air tests of the CFTL rod. 


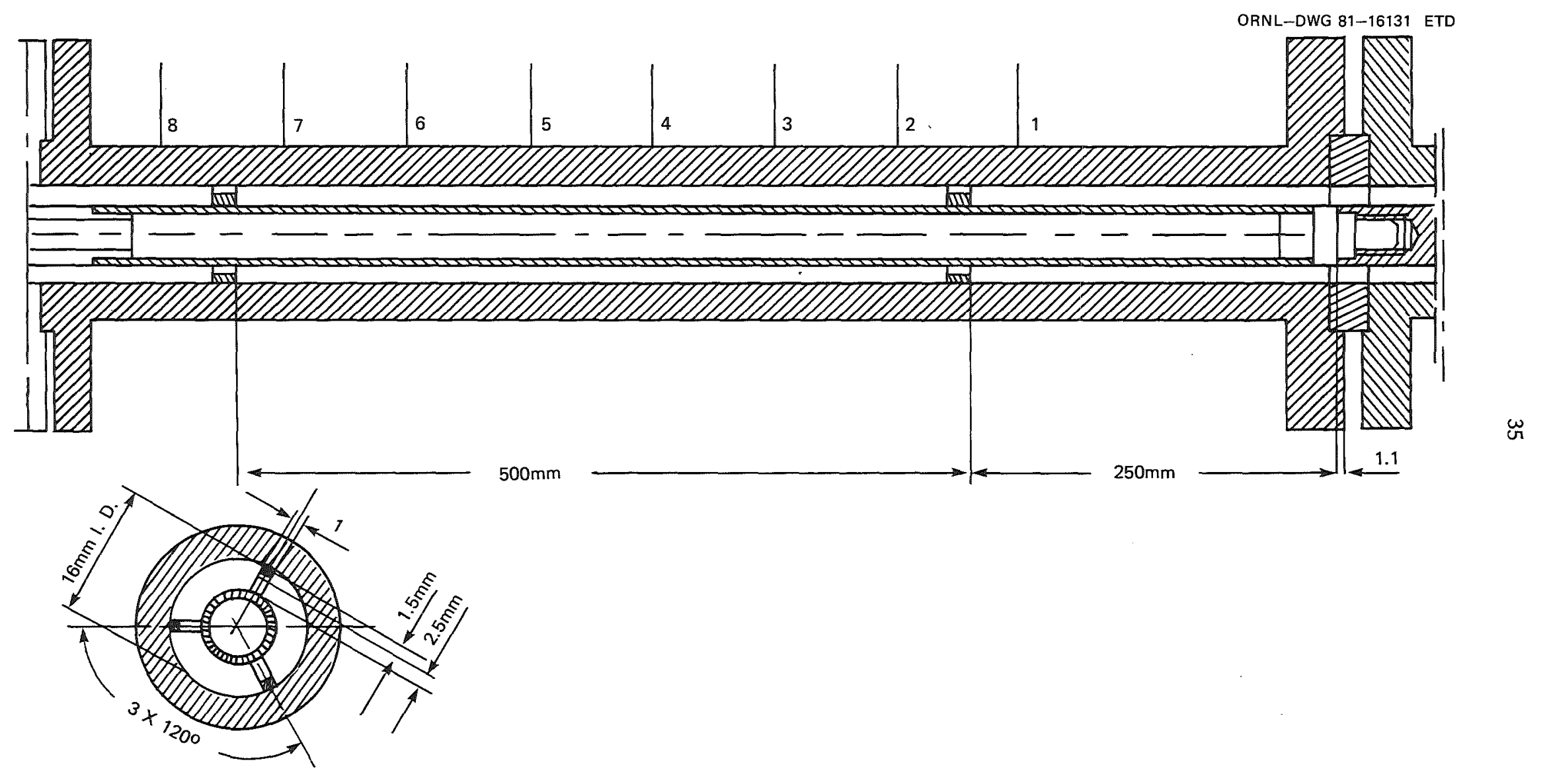

Fig. B-2. Placement of the CFTL rod within the smooth tube. 
The test data were processed at ORNL using the KfK code AURIS, which converts the experimentally measured values of pressure and temperature at several axial locations along the test section into an overall friction factor and Stanton number for the rough rod-smooth tube combination. The subsequent transformation of these values into the friction factor and Stanton number applicable to the region between the rough surface and the surface of zero shear in the adjacent flow is also performed by AURIS. 
Appendix C

EXPERIMENTAL RESULTS 


$$
\cdot
$$


EXPERIMENTAL RESULTS-ISOTHERMAL TESTS

\begin{tabular}{|c|c|c|c|c|c|c|c|c|}
\hline Shroud & $\begin{array}{l}\text { Test } \\
\text { No. }\end{array}$ & $\operatorname{Re} \times 10^{-4}$ & f & $\mathrm{Y}_{\mathrm{L}} / \mathrm{h}$ & $\mathrm{h}^{+}$ & $f_{1}$ & Eq. (4) & $\sqrt{2 / f_{1}}$ \\
\hline \multirow[t]{25}{*}{20} & 1 & 24.46 & 0.00697 & 29.48 & 211.5 & 0.01368 & 2.548 & 12.090 \\
\hline & 2 & 19.91 & 0.00723 & 29.39 & 174.9 & 0.01413 & 2.545 & 11.898 \\
\hline & 3 & 17.04 & 0.00738 & 29.23 & 150.7 & 0.01432 & 2.539 & 11.818 \\
\hline & 4 & 14.64 & 0.00753 & 29.06 & 130.2 & 0.01448 & 2.532 & 11.751 \\
\hline & 5 & 11.81 & 0.00766 & 28.65 & 105.0 & 0.01444 & 2.516 & 11.768 \\
\hline & 6 & 11.10 & 0.00765 & 28.43 & 98.1 & 0.01427 & 2.508 & 11.840 \\
\hline & 7 & 10.16 & 0.00778 & 28.40 & 90.5 & 0.01450 & 2.507 & 11.745 \\
\hline & 8 & 7.38 & 0.00802 & 27.79 & 65.8 & 0.01448 & 2.482 & 11.754 \\
\hline & 9 & 6.43 & 0.00811 & 27.47 & 57.2 & 0.01439 & 2.470 & 11.791 \\
\hline & 10 & 5,91 & 0.00821 & 27.37 & 52.8 & 0.01450 & 2.466 & 11.744 \\
\hline & 11 & 4.74 & 0.00849 & 27.09 & 42.7 & 0.01477 & 2.454 & 11.636 \\
\hline & 12 & 3.84 & 0.00859 & 26.48 & 34.4 & 0.01445 & 2.429 & 11.764 \\
\hline & 13 & 3.12 & 0.00891 & 26.24 & 28.2 & 0.01479 & 2.419 & 11.631 \\
\hline & 14 & 2.71 & 0.00890 & 25.64 & 24.1 & 0.01427 & 2.393 & 11.837 \\
\hline & 15 & 2.30 & 0.00931 & 25.72 & 21.0 & 0.01502 & 2.397 & 11.540 \\
\hline & 16 & 1.99 & 0.00938 & 25.23 & 18.1 & 0.01470 & 2.375 & 11.665 \\
\hline & 17 & 1.67 & 0.00950 & 24.64 & 15.0 & 0.01438 & 2.350 & 11.795 \\
\hline & 18 & 1.21 & 0.00985 & 23.73 & 10.8 & 0.01409 & 2.308 & 11.916 \\
\hline & 19 & 1.20 & 0.00976 & 23.52 & 10.6 & 0.01377 & 2.298 & 12.052 \\
\hline & 20 & 0.88 & 0.01022 & 22.73 & 7.7 & 0.01370 & 2.261 & 12.084 \\
\hline & 21 & 0.63 & 0.01061 & 21.61 & 5.5 & 0.01319 & 2.205 & 12.314 \\
\hline & 22 & 0.47 & 0.01057 & 19.61 & 3.9 & 0.01137 & 2.099 & 13.264 \\
\hline & 23 & 0.34 & 0.01000 & 15.58 & 2.4 & 0.00774 & 1.847 & 16.073 \\
\hline & 24 & 0.26 & 0.00976 & 11.82 & 1.5 & 0.00520 & 1.545 & 19.610 \\
\hline & 25 & 0.19 & 0.01246 & 16.75 & 1.5 & 0.01058 & 1.927 & 13.748 \\
\hline \multirow[t]{17}{*}{16} & 1 & 13.38 & 0.00877 & 20.89 & 188.9 & 0.01655 & 2.168 & 10.992 \\
\hline & 2 & 7.42 & 0.00931 & 20.30 & 106.0 & 0.01691 & 2.136 & 10.876 \\
\hline & 3 & 4.60 & 0.00980 & 19.78 & 66.3 & 0.01720 & 2.108 & 10.783 \\
\hline & 4 & 3.25 & 0.01014 & 19.33 & 47.0 & 0.01725 & 2.083 & 10.767 \\
\hline & 5 & 2.20 & 0.01063 & 18.86 & 32.0 & 0.01748 & 2.056 & 10.696 \\
\hline & 6 & 1.68 & 0.01080 & 18.34 & 24.3 & 0.01708 & 2.026 & 10.821 \\
\hline & 7 & 1.22 & 0.01107 & 17.71 & 17.4 & 0.01666 & 1.988 & 10.957 \\
\hline & 8 & 1.21 & 0.01107 & 17.70 & 17.3 & 0.01665 & 1.987 & 10.960 \\
\hline & 9 & 0.91 & 0.01152 & 17.28 & 13.0 & 0.01675 & 1.961 & 10.928 \\
\hline & 10 & 0.66 & 0.01178 & 16.51 & 9.3 & 0.01605 & 1.912 & 11.164 \\
\hline & 11 & 0.50 & 0.01166 & 15.42 & 6.7 & 0.01440 & 1.838 & 11.786 \\
\hline & 12 & 0.33 & 0.01189 & 13.99 & 4.2 & 0.01281 & 1.732 & 12.496 \\
\hline & 13 & 0.33 & 0.01157 & 13.63 & 4.1 & 0.01202 & 1.703 & 12.902 \\
\hline & 14 & 0.24 & 0.01184 & 12.54 & 2.9 & 0.01097 & 1.612 & 13.499 \\
\hline & 15 & 0.19 & 0.01341 & 13.18 & 2.5 & 0.01319 & 1.668 & 12.312 \\
\hline & 16 & 0.14 & 0.01790 & 15.60 & 2.3 & 0.02242 & 1.850 & 9.444 \\
\hline & 17 & 0.09 & 0.02758 & 18.50 & 2.1 & 0.04485 & 2.035 & 6.678 \\
\hline \multirow[t]{16}{*}{13} & 1 & 8.75 & 0.01166 & 14.38 & 220.1 & 0.02192 & 1.762 & 9.553 \\
\hline & 2 & 5.21 & 0.01215 & 14.04 & 131.9 & 0.02215 & 1.736 & 9.502 \\
\hline & 3 & 5.00 & 0.01226 & 14.04 & 127.2 & 0.02237 & 1.736 & 9.455 \\
\hline & 4 & 3.12 & 0.01276 & 13.69 & 79.6 & 0.02255 & 1.709 & 9.417 \\
\hline & 5 & 2.16 & 0.01324 & 13.42 & 55.5 & 0.02284 & 1.688 & 9.357 \\
\hline & 6 & 1.48 & 0.01381 & 13.13 & 38.3 & 0.02317 & 1.664 & 9.291 \\
\hline & 7 & 1.48 & 0.01371 & 13.10 & 38.2 & 0.02292 & 1.662 & 9.341 \\
\hline & 8 & 1.07 & 0.01411 & 12.79 & 27.6 & 0.02288 & 1.636 & 9.350 \\
\hline & 9 & 0.76 & 0.01432 & 12.36 & 19.4 & 0.02217 & 1.599 & 9.497 \\
\hline & 10 & 0.51 & 0.01435 & 11.68 & 12.6 & 0.02058 & 1.539 & 9.858 \\
\hline & 11 & 0.37 & 0.01485 & 11.29 & 9.1 & 0.02031 & 1.502 & 9.923 \\
\hline & 12 & 0.37 & 0.01428 & 11.06 & 8.9 & 0.01899 & 1.481 & 10.261 \\
\hline & 13 & 0.28 & 0.01434 & 10.44 & 6.4 & 0.01762 & 1.420 & .10 .653 \\
\hline & 14 & 0.20 & 0.01352 & 9.13 & 4.1 & 0.01382 & 1.276 & 12.031 \\
\hline & 15 & 0.14 & 0.01813 & 10.54 & 3.7 & 0.02259 & 1.429 & 9.410 \\
\hline & 16 & 0.10 & 0.02602 & 11.91 & 3.3 & 0.03872 & 1.560 & 7.187 \\
\hline
\end{tabular}


EXPERIMENTAL RESULTS-HEATED TESTS-T ${ }_{W M}=150^{\circ} \mathrm{C}$

\begin{tabular}{ccccccccc}
\hline \multirow{2}{*}{ Shroud } & $\begin{array}{l}\text { Test } \\
\text { No. }\end{array}$ & $\mathrm{Re} \times 10^{-4}$ & $\mathrm{f}$ & $\mathrm{Y}_{\mathrm{L}} / \mathrm{h}$ & $\mathrm{h}^{+}$ & $\mathrm{f}_{1}$ & Eq. $(4)$ & $\sqrt{2 / \mathrm{f}_{\mathrm{I}}}$ \\
& & & & & & & & \\
\hline \multirow{2}{*}{20} & 1 & 15.80 & 0.00716 & 28.30 & 81.8 & 0.01366 & 2.502 & 12.099 \\
& 2 & 10.06 & 0.00752 & 27.56 & 52.6 & 0.01384 & 2.473 & 12.021 \\
& 3 & 6.87 & 0.00778 & 26.75 & 36.0 & 0.01373 & 2.440 & 12.068 \\
& 4 & 5.21 & 0.00797 & 26.13 & 27.3 & 0.01366 & 2.414 & 12.101 \\
& 5 & 3.47 & 0.00826 & 25.07 & 18.1 & 0.01330 & 2.368 & 12.264 \\
& 6 & 2.38 & 0.00875 & 24.45 & 12.7 & 0.01360 & 2.341 & 12.126 \\
& 7 & 1.27 & 0.00947 & 22.87 & 6.8 & 0.01335 & 2.267 & 12.238 \\
& 8 & 1.13 & 0.00979 & 22.89 & 6.1 & 0.01380 & 2.268 & 12.039 \\
& 9 & 0.94 & 0.00996 & 22.24 & 5.0 & 0.01348 & 2.236 & 12.179 \\
& 10 & 0.75 & 0.01030 & 21.69 & 4.1 & 0.01342 & 2.209 & 12.208 \\
& 11 & 0.60 & 0.01062 & 20.99 & 3.2 & 0.01322 & 2.173 & 12.300 \\
12 & 0.46 & 0.01074 & 19.55 & 2.4 & 0.01210 & 2.095 & 12.854 \\
& 13 & 0.36 & 0.01023 & 16.53 & 1.6 & 0.00916 & 1.912 & 14.774 \\
14 & 0.26 & 0.01218 & 18.03 & 1.4 & 0.01331 & 1.977 & 12.258 \\
15 & 0.30 & 0.01076 & 13.73 & 1.3 & 0.00955 & 1.514 & 14.472 \\
\hline
\end{tabular}

\begin{tabular}{|c|c|c|c|c|c|c|c|c|}
\hline Shroud & $\begin{array}{l}\text { Test } \\
\text { No. }\end{array}$ & $S_{t}$ & $T_{W} / T_{B}$ & $\frac{T_{W}-T_{B I}}{T W-T B}$ & $\beta$ & $S_{1_{1}}$ & $\sqrt{2 / f_{1} /} S_{i_{1}}$ & $\begin{array}{c}\text { Heat } \\
\text { balance } \\
\text { error }(\div)\end{array}$ \\
\hline \multirow[t]{15}{*}{20} & 1 & 0.00400 & 1.342 & 0.933 & 0.760 & 0.00438 & 18.849 & 1.7 \\
\hline & 2 & 0.00417 & 1.341 & 0.926 & 0.751 & 0.00460 & 18.075 & 0.5 \\
\hline & 3 & 0.00426 & 1.338 & 0.919 & 0.740 & 0.00472 & 17.531 & 1.0 \\
\hline & 4 & 0.00439 & 1.337 & 0.916 & 0.732 & 0.00488 & 16.929 & 0.5 \\
\hline & 5 & 0.00430 & 1.335 & 0.906 & 0.718 & 0.00481 & 16.951 & 1.4 \\
\hline & 6 & 0.00438 & 1.328 & 0.901 & 0.710 & 0.00492 & $16.76 !$ & 0.6 \\
\hline & 7 & 0.00442 & 1.326 & 0.885 & 0.690 & 0.00502 & 16.293 & 3.0 \\
\hline & 8 & 0.00437 & 1.324 & 0.886 & 0.690 & 0.00494 & 16.820 & 2.1 \\
\hline & 9 & 0.00441 & 1.331 & 0.880 & 0.682 & 0.00501 & 16.379 & 4.6 \\
\hline & 10 & 0.00435 & 1.319 & 0.879 & 0.674 & 0.00494 & 16.596 & 5.2 \\
\hline & 11 & 0.00423 & 1.327 & 0.881 & 0.665 & 0.00477 & 17.044 & 7.0 \\
\hline & 12 & 0.00410 & 1.328 & 0.875 & 0.647 & 0.00463 & 16.816 & 9.8 \\
\hline & 13 & 0.00377 & 1.333 & 0.854 & 0.607 & 0.00429 & 15.777 & 12.3 \\
\hline & 14 & 0.00384 & 1.315 & 0.888 & 0.627 & 0.00434 & 18.794 & 17.6 \\
\hline & 15 & 0.00374 & 1.309 & 0.638 & 0.571 & 0.00608 & 11.363 & 15.9 \\
\hline
\end{tabular}

\begin{tabular}{|c|c|c|c|c|c|c|c|c|}
\hline Shroud & $\begin{array}{l}\text { Test } \\
\text { No. }\end{array}$ & $\operatorname{Re} \times 10^{-4}$ & f & $Y_{L} / h$ & $\mathrm{~h}^{+}$ & $f_{l}$ & Eq. (4) & $\sqrt{2 / f_{1}}$ \\
\hline \multirow[t]{13}{*}{16} & 1 & 11.88 & 0.00882 & 20.59 & 108.5 & 0.01673 & 2.152 & 10.933 \\
\hline & 2 & 7.42 & 0.00905 & 19.92 & 68.3 & 0.01645 & 2.116 & 11.027 \\
\hline & 3 & 5.32 & 0.00934 & 19.53 & 49.5 & 0.01655 & 2.094 & 10.993 \\
\hline & 4 & 3.33 & $0.0098 !$ & 18.96 & 31.5 & 0.01671 & 2.062 & 10.941 \\
\hline & 5 & 2.13 & 0.01000 & 18.03 & 19.8 & 0.01590 & 2.007 & 11.217 \\
\hline & 6 & 1.59 & 0.01048 & 17.77 & 15.1 & 0.01638 & 1.991 & 11.051 \\
\hline & 7 & 1.16 & 0.01074 & 17.12 & 10.8 & 0.01596 & 1.951 & 11.195 \\
\hline & 8 & 1.14 & 0.01073 & 17.07 & 10.7 & 0.01588 & 1.948 & 11.222 \\
\hline & 9 & 0.82 & 0.01135 & 16.72 & 7.8 & 0.01633 & 1.925 & 11.066 \\
\hline & 10 & 0.59 & 0.01164 & 15.93 & 5.6 & 0.01567 & 1.873 & 11.298 \\
\hline & 11 & 0.47 & 0.01138 & 14.81 & 4.2 & 0.01385 & 1.793 & 12.018 \\
\hline & 12 & 0.35 & 0.01144 & 13.78 & 3.0 & 0.01270 & 1.714 & 12.550 \\
\hline & 13 & 0.31 & 0.01182 & 13.64 & 2.7 & 0.01293 & 1.703 & 12.435 \\
\hline
\end{tabular}


HEATED TESTS $-T_{\mathrm{w}_{\mathrm{M}}}=150^{\circ} \mathrm{C}$ (cont'd)

\begin{tabular}{|c|c|c|c|c|c|c|c|c|}
\hline Shroud & $\begin{array}{l}\text { Test } \\
\text { No. }\end{array}$ & $\mathrm{S}_{\mathrm{t}}$ & $T_{w} / T_{B}$ & $\underbrace{\mathrm{TW}-\mathrm{TB}}_{\mathrm{T}-\mathrm{T}_{\mathrm{BI}}}$ & $\beta$ & $S_{t_{1}}$ & $\sqrt{2 / f_{1} /} S_{i_{1}}$ & $\begin{array}{c}\text { Heat } \\
\text { balance } \\
\text { error }(\%)\end{array}$ \\
\hline \multirow[t]{13}{*}{16} & 1 & 0.00435 & 1.288 & 0.951 & 0.825 & 0.00471 & 19.432 & 0.2 \\
\hline & 2 & 0.00463 & 1.276 & 0.943 & 0.814 & 0.00505 & 17.974 & 0.9 \\
\hline & 3 & 0.00476 & 1.271 & 0.941 & 0.808 & 0.00520 & 17.497 & 1.1 \\
\hline & 4 & 0.00480 & 1.263 & 0.936 & 0.798 & 0.00526 & 17.363 & 2.8 \\
\hline & 5 & 0.00482 & 1.262 & 0.924 & 0.783 & 0.00533 & 16.718 & 2.5 \\
\hline & 6 & 0.00493 & 1.258 & 0.928 & 0.779 & 0.00543 & 16.663 & 0.3 \\
\hline & 7 & 0.00494 & 1.263 & 0.921 & 0.769 & 0.00546 & 16.346 & 1.3 \\
\hline & 8 & 0.00496 & 1.256 & 0.921 & 0.768 & 0.00549 & 16.245 & 2.0 \\
\hline & 9 & 0.00494 & 1.258 & 0.923 & 0.762 & 0.00545 & 16.594 & 4.8 \\
\hline & 10 & 0.00486 & 1.252 & 0.918 & 0.749 & 0.00536 & 16.513 & 7.6 \\
\hline & 11 & 0.00462 & 1.256 & 0.909 & 0.731 & 0.00509 & 16.332 & 9.7 \\
\hline & 12 & 0.00418 & 1.255 & 0.927 & 0.714 & 0.00452 & 17.636 & 12.0 \\
\hline & 13 & 0.00402 & 1.245 & 0.938 & 0.712 & 0.00429 & 18.753 & 11.2 \\
\hline
\end{tabular}

\begin{tabular}{ccccccccc}
\hline \multirow{2}{*}{ Shroud } & $\begin{array}{c}\text { Test } \\
\text { No. }\end{array}$ & Re $\times 10^{-4}$ & $f$ & $Y_{L} / h$ & $h^{+}$ & $f_{1}$ & Eq. (4) & $\sqrt{2 / f_{1}}$ \\
\hline \multirow{2}{*}{13} & 1 & 8.06 & 0.01153 & 14.22 & 145.7 & 0.02177 & 1.750 & 9.584 \\
& 2 & 5.35 & 0.01206 & 14.00 & 101.6 & 0.02236 & 1.733 & 9.457 \\
& 3 & 3.44 & 0.01249 & 13.67 & 65.6 & 0.02253 & 1.708 & 9.421 \\
& 4 & 2.16 & 0.01310 & 13.34 & 41.9 & 0.02294 & 1.681 & 9.338 \\
& 5 & 1.90 & 0.01307 & 13.16 & 36.7 & 0.02248 & 1.667 & 9.432 \\
& 6 & 1.88 & 0.01310 & 13.14 & 36.0 & 0.02243 & 1.665 & 9.443 \\
& 7 & 1.30 & 0.01343 & 12.79 & 25.2 & 0.02228 & 1.636 & 9.475 \\
& 8 & 0.82 & 0.01353 & 12.14 & 15.4 & 0.02104 & 1.580 & 9.749 \\
& 9 & 0.54 & 0.01342 & 11.37 & 9.7 & 0.01918 & 1.510 & 10.212 \\
& 10 & 0.36 & 0.01344 & 10.64 & 6.2 & 0.01766 & 1.440 & 10.641 \\
& 11 & 0.35 & 0.01354 & 10.59 & 6.0 & 0.01766 & 1.435 & 10.641 \\
& 12 & 0.26 & 0.01293 & 9.67 & 4.0 & 0.01515 & 1.337 & 11.492 \\
\hline
\end{tabular}

\begin{tabular}{|c|c|c|c|c|c|c|c|c|}
\hline Shroud & $\begin{array}{l}\text { Test } \\
\text { No. }\end{array}$ & $\mathrm{S}_{\mathrm{t}}$ & $\mathrm{T}_{\mathrm{W}} / \mathrm{T}_{\mathrm{B}}$ & $\frac{T w-T_{B} 1}{T W-T B}$ & $\beta$ & $S_{t_{1}}$ & $\sqrt{2 / f_{1}} / S_{t_{l}}$ & $\begin{array}{c}\text { Heat } \\
\text { balance } \\
\text { error }(\%)\end{array}$ \\
\hline \multirow[t]{12}{*}{13} & 1 & 0.00495 & 1.205 & 0.984 & 0.882 & 0.00523 & 19.953 & 0.3 \\
\hline & 2 & 0.00541 & 1.179 & 0.984 & 0.878 & 0.00572 & 18.499 & 0.5 \\
\hline & 3 & 0.00572 & 1.179 & 0.980 & 0.871 & 0.00607 & 17.490 & 0.6 \\
\hline & 4 & 0.00589 & 1.174 & 0.977 & 0.865 & 0.00626 & 17.109 & 1.0 \\
\hline & 5 & 0.00598 & 1.172 & 0.970 & 0.861 & 0.00640 & 16.577 & 1.3 \\
\hline & 6 & 0.00581 & 1.176 & 0.959 & 0.861 & 0.00627 & 16.902 & 0.3 \\
\hline & 7 & 0.00611 & 1.167 & 0.968 & 0.854 & 0.00654 & 16.148 & 2.4 \\
\hline & 8 & 0.00620 & 1.167 & 0.971 & 0.841 & 0.00659 & 15.559 & 5.3 \\
\hline & 9 & 0.00609 & 1.169 & 0.971 & 0.826 & 0.00645 & 15.176 & 9.6 \\
\hline & 10 & 0.00536 & 1.184 & 0.986 & 0.811 & 0.00557 & 16.864 & 15.2 \\
\hline & 11 & 0.00537 & 1.173 & 0.991 & 0.810 & 0.00555 & 16.939 & 12.9 \\
\hline & 12 & 0.00432 & 1.195 & 1.041 & 0.792 & 0.00425 & 20.480 & 24.3 \\
\hline
\end{tabular}


EXPERIMENTAL RESULTS-HEATED TESTS $-\mathrm{T}_{W M}=350^{\circ} \mathrm{C}$

\begin{tabular}{ccccccccc}
\hline \multirow{2}{*}{ Shroud } & $\begin{array}{c}\text { Test } \\
\text { No. }\end{array}$ & $R e \times 10^{-4}$ & $f$ & $Y_{1} \cdot h$ & $h^{+}$ & $f_{1}$ & Eq. (4) & $\sqrt{2 f_{1}}$ \\
\hline \multirow{2}{*}{20} & 1 & 25.72 & 0.00604 & 26.89 & 74.2 & 0.01122 & 2.445 & 13.351 \\
& 2 & 14.54 & 0.00693 & 27.25 & 45.6 & 0.01310 & 2.460 & 12.355 \\
& 3 & 14.11 & 0.00693 & 27.16 & 44.0 & 0.01306 & 2.457 & 12.375 \\
& 4 & 10.62 & 0.00712 & 26.62 & 3.3 .4 & 0.01308 & 2.434 & 12.366 \\
& 5 & 6.88 & 0.00737 & 25.58 & 21.6 & 0.01282 & 2.390 & 12.492 \\
& 6 & 4.70 & 0.00760 & 24.62 & 14.8 & 0.01256 & 2.348 & 12.619 \\
& 7 & 3.99 & 0.00768 & 24.04 & 12.5 & 0.01226 & 2.322 & 12.775 \\
& 8 & 2.80 & 0.00817 & 23.60 & 9.1 & 0.01267 & 2.301 & 12.562 \\
& 9 & 2.81 & 0.00802 & 23.24 & 9.0 & 0.01217 & 2.284 & 12.821 \\
& 10 & 1.69 & 0.00889 & 22.78 & 5.6 & 0.01305 & 2.262 & 12.379 \\
& 11 & 1.15 & 0.00950 & 22.07 & 3.9 & 0.01329 & 2.227 & 12.267 \\
12 & 0.82 & 0.01005 & 21.34 & 2.8 & 0.01333 & 2.191 & 12.248 \\
& 13 & 0.61 & 0.01065 & 20.91 & 2.1 & 0.01374 & 2.168 & 12.063 \\
14 & 0.47 & 0.01154 & 20.99 & 1.7 & 0.01520 & 2.169 & 11.469 \\
15 & 0.34 & 0.01081 & 17.70 & 1.1 & 0.01125 & 1.986 & 13.336 \\
\hline
\end{tabular}

\begin{tabular}{|c|c|c|c|c|c|c|c|c|}
\hline Shroud & $\begin{array}{l}\text { Test } \\
\text { No. }\end{array}$ & $\mathrm{S}_{\mathrm{l}}$ & $T_{W} / T_{B}$ & $\frac{T_{W-} T_{B 1}}{T W-T B}$ & $\beta$ & $S_{1}$ & $\sqrt{2 / \mathrm{f}_{1}} / S_{1_{t}}$ & $\begin{array}{c}\text { Heat } \\
\text { balanec } \\
\text { error(\%) }\end{array}$ \\
\hline \multirow[t]{15}{*}{20} & I & 0.00346 & 1.795 & 0.933 & 0.743 & 0.00381 & 19.636 & 13.1 \\
\hline & 2 & 0.00370 & 1.789 & 0.935 & 0.748 & 0.00408 & 19.832 & 1.1 \\
\hline & 3 & 0.00371 & 1.792 & 0.934 & 0.747 & 0.00409 & 19.755 & 0.9 \\
\hline & 4 & 0.00380 & 1.785 & 0.930 & 0.740 & 0.00416 & 19.250 & 0.5 \\
\hline & 5 & 0.00380 & 1.781 & 0.924 & 0.726 & 0.00418 & 18.973 & 0.5 \\
\hline & 6 & 0.00380 & 1.769 & 0.919 & $0.7 / 4$ & 0.00418 & 18.742 & 0.0 \\
\hline & 7 & $0.0038 !$ & 1.769 & 0.911 & 0.706 & 0.00433 & 18.368 & 0.5 \\
\hline & 8 & 0.00385 & 1.754 & 0.908 & 0.700 & 0.00422 & 18.493 & 1.6 \\
\hline & 9 & 0.00385 & 1.745 & 0.902 & 0.696 & 0.00447 & 18.068 & 1.2 \\
\hline & 10 & 0.00384 & 1.745 & 0.900 & 0.690 & 0.00434 & 18.797 & 1.3 \\
\hline & 11 & 0.00382 & 1.744 & 0.895 & 0.680 & 0.00428 & 19.074 & 3.5 \\
\hline & 12 & 0.00371 & 1.735 & 0.893 & 0.671 & 0.00420 & 19.737 & 4.9 \\
\hline & 13 & 0.00357 & 1.742 & 0.901 & 0.665 & 0.00395 & 20.979 & 8.1 \\
\hline & 14 & 0.00358 & 1.723 & 0.911 & 0.666 & 0.00396 & 22,000 & 10.7 \\
\hline & 15 & 0.00329 & 1.710 & 0.903 & 0.624 & 0.00362 & 20.738 & 15.0 \\
\hline
\end{tabular}

\begin{tabular}{crrrrrrrr}
\hline \multirow{2}{*}{ Shroud } & Test & $\mathrm{Re} \times 10^{-4}$ & $\mathrm{f}$ & $\mathrm{Y}_{\mathrm{I}} / \mathrm{h}$ & $\mathrm{h}^{+}$ & $\mathrm{f}_{\mathrm{I}}$ & $\mathrm{Eq} .(4)$ & $\sqrt{2 / \mathrm{f}_{1}}$ \\
& No. & & & & & & & \\
\hline \multirow{2}{*}{16} & 1 & 10.63 & 0.00851 & 19.99 & 64.0 & 0.01614 & 2.119 & 11.131 \\
& 2 & 7.48 & 0.00886 & 19.66 & 46.2 & 0.01644 & 2.101 & 11.028 \\
& 3 & 4.78 & 0.00920 & 19.11 & 29.7 & 0.01658 & 2.070 & 10.983 \\
& 4 & 3.57 & 0.00941 & 18.66 & 22.5 & 0.01643 & 2.044 & 11.033 \\
& 5 & 2.55 & 0.00967 & 18.12 & 16.2 & 0.01623 & 2.012 & 11.100 \\
& 6 & 1.87 & 0.00983 & 17.46 & 11.7 & 0.01572 & 1.972 & 11.280 \\
& 7 & 1.22 & 0.01031 & 16.73 & 7.6 & 0.01549 & 1.925 & 11.364 \\
& 8 & 1.21 & 0.01033 & 16.73 & 7.6 & 0.01551 & 1.925 & 11.357 \\
9 & 0.83 & 0.01113 & 16.42 & 5.3 & 0.01628 & 1.905 & 11.084 \\
& 10 & 0.61 & 0.01147 & 15.83 & 4.0 & 0.01597 & 1.866 & 11.189 \\
& 11 & 0.43 & 0.01154 & 14.76 & 2.6 & 0.01472 & 1.789 & 11.657 \\
12 & 0.31 & 0.01230 & 14.59 & 2.0 & 0.01560 & 1.777 & 11.322 \\
13 & 0.27 & 0.01217 & 14.08 & 1.6 & 0.01491 & 1.739 & 11.582 \\
\hline
\end{tabular}


HEATED TESTS $-\mathrm{T}_{W M}=350^{\circ} \mathrm{C}$ (cont'd)

\begin{tabular}{|c|c|c|c|c|c|c|c|c|}
\hline Shroud & $\begin{array}{l}\text { Test } \\
\text { No. }\end{array}$ & $S_{1}$ & $T_{W} / T_{H}$ & $\frac{T_{W}-T_{B I}}{T W-T B}$ & $\beta$ & $S_{1_{1}}$ & $\sqrt{2 / f_{1}} / S_{t_{1}}$ & $\begin{array}{c}\text { Heat } \\
\text { balance } \\
\text { error }(\%)\end{array}$ \\
\hline \multirow[t]{13}{*}{16} & 1 & 0.00417 & 1.630 & 0.960 & 0.816 & 0.00454 & 19.805 & 0.9 \\
\hline & 2 & 0.00425 & 1.613 & 0.958 & 0.811 & 0.00462 & 19.622 & 1.2 \\
\hline & 3 & 0.00439 & 1.609 & 0.959 & 0.802 & 0.00479 & 19.024 & 1.2 \\
\hline & 4 & 0.00446 & 1.591 & 0.955 & 0.795 & 0.00488 & 18.587 & 0.8 \\
\hline & 5 & 0.00447 & 1.584 & 0.949 & 0.786 & 0.00490 & 18.394 & 0.3 \\
\hline & 6 & 0.00445 & 1.589 & 0.941 & 0.775 & 0.00490 & 18.097 & 1.0 \\
\hline & 7 & $0.0043 !$ & 1.593 & 0.930 & 0.763 & 0.00475 & 18.522 & 0.2 \\
\hline & 8 & 0.00432 & 1.591 & 0.931 & 0.763 & 0.00477 & 18.449 & 0.2 \\
\hline & 9 & 0.00431 & $1.58 !$ & 0.933 & 0.758 & 0,00474 & 19.035 & 2.9 \\
\hline & 10 & 0.00416 & 1.577 & 0.933 & 0.749 & 0.00455 & 19.635 & 4.6 \\
\hline & 11 & 0.00378 & 1.589 & 0.945 & 0.731 & 0.00407 & 21.067 & 9.9 \\
\hline & 12 & 0.00364 & 1.560 & 0.975 & 0.729 & 0.00386 & 22.868 & 10.7 \\
\hline & 13 & 0.00338 & 1.583 & 0.997 & 0.720 & 0.00354 & 24.420 & 14.1 \\
\hline
\end{tabular}

\begin{tabular}{rrrrrrrrrr}
\hline \multirow{2}{*}{ Shroud } & $\begin{array}{c}\text { Test } \\
\text { No, }\end{array}$ & $\operatorname{Re} \times 10^{-4}$ & $\mathrm{f}$ & $\mathrm{Y}_{\mathrm{l}} / \mathrm{h}$ & $\mathrm{h}^{+}$ & $\mathrm{f}_{1}$ & Eq. (4) & $\sqrt{2 / \mathrm{f}_{\mathrm{i}}}$ \\
\hline \multirow{2}{*}{1.3} & 1 & 4.59 & 0.01214 & 13.81 & 65.2 & 0.02272 & 1.718 & 9.383 \\
& 2 & 2.95 & 0.01259 & 13.51 & 43.2 & 0.02306 & 1.694 & 9.312 \\
& 3 & 2.04 & 0.01298 & 13.21 & 30.5 & 0.02318 & 1.670 & 9.289 \\
& 4 & 1.34 & 0.01349 & 12.81 & 20.1 & 0.02307 & 1.637 & 9.311 \\
& 5 & 1.30 & 0.01319 & 12.70 & 19.6 & 0.02248 & 1.628 & 9.433 \\
& 6 & 0.86 & 0.01333 & 12.14 & 12.7 & 0.02141 & 1.580 & 9.666 \\
& 7 & 0.61 & 0.01322 & 11.52 & 8.7 & 0.01992 & 1.524 & 10.021 \\
& 8 & 0.42 & 0.01237 & 10.36 & 5.3 & 0.01624 & 1.411 & 11.096 \\
& 9 & 0.30 & 0.01267 & 9.91 & 3.6 & 0.01593 & 1.364 & 11.204 \\
& 10 & 0.30 & 0.01258 & 9.91 & 3.6 & 0.01593 & 1.364 & 11.204 \\
& 11 & 0.23 & 0.01324 & 9.87 & 2.7 & 0.01697 & 1.359 & 10.857 \\
\hline
\end{tabular}

\begin{tabular}{|c|c|c|c|c|c|c|c|c|}
\hline Shroud & $\begin{array}{l}\text { Test } \\
\text { No. }\end{array}$ & $S_{1}$ & $T_{W} / T_{B}$ & $\frac{T_{11}-T_{B \mathbb{1}}}{T W-T B}$ & $\beta$ & $S_{1}$ & $\sqrt{2 / f_{1} /} S_{1_{1}}$ & $\begin{array}{c}\text { Heat } \\
\text { balance } \\
\text { erron }(\%)\end{array}$ \\
\hline \multirow[t]{11}{*}{13} & I & 0.00518 & 1.407 & 0.982 & 0.875 & 0.00554 & 19.247 & 0.4 \\
\hline & 2 & 0.00557 & 1.382 & 0.991 & 0.869 & 0.00592 & 18.141 & 1.3 \\
\hline & 3 & 0.00580 & 1.368 & 0.991 & 0.863 & 0.00618 & 17.428 & 1.9 \\
\hline & 4 & 0.00561 & 1.364 & 0.975 & 0.855 & 0.00602 & 17.828 & 0.8 \\
\hline & 5 & 0.00595 & 1.350 & 0.990 & 0.853 & 0.00633 & 16.744 & 4.3 \\
\hline & 6 & 0.00579 & 1.351 & 0.980 & 0.842 & 0.00619 & 16.701 & 5.7 \\
\hline & 7 & 0.00566 & 1.355 & 0.976 & 0.829 & 0.00606 & 16.470 & 8.6 \\
\hline & 8 & 0.00484 & 1.377 & 0.968 & 0.807 & 0.00516 & 17.461 & 10.8 \\
\hline & 9 & 0.00411 & 1.405 & 1.008 & 0.798 & 0.00423 & 21.076 & 14.2 \\
\hline & 10 & 0.00421 & 1.399 & 1.021 & 0.798 & 0.00430 & 20.741 & 17.7 \\
\hline & 11 & 0.00368 & 1.428 & 1.071 & 0.797 & 0.00368 & 25.019 & 22.7 \\
\hline
\end{tabular}

